\title{
Motor Activity in the Isolated Spinal Cord of the Chick Embryo: Synaptic Drive and Firing Pattern of Single Motoneurons
}

\author{
Michael J. O'Donovan \\ Department of Physiology and Biophysics, University of lowa, lowa City, lowa 52242
}

The cellular mechanisms underlying embryonic motility were investigated using intracellular recording from motoneurons and electrotonic recording from muscle nerves during motor activity generated by an isolated spinal cord preparation of 12- to 15-d-old chick embryos. DC-coupled recordings from sartorius (a flexor) and femorotibialis (an extensor) muscle nerves revealed that both sets of motoneurons were depolarized at the same time in each cycle even when the motoneurons fired out of phase. Sartorius motoneurons fired briefly on the rising phase of the depolarization and then stopped firing before discharging a second burst of spikes as the depolarization decayed. By contrast, femorotibialis motoneurons fired at the peak of their depolarization, which was coincident with the interruption in sartorius activity.

Intracellular recordings from antidromically identified motoneurons confirmed that flexor and extensor motoneurons were depolarized at the same time during each cycle of activity. The discharge of femorotibialis motoneurons, and others presumed to be extensors, followed changes in membrane potential so that maximal firing occurred during peak depolarization. The relationship between discharge and membrane potential was different in sartorius motoneurons (and in others presumed to be flexors) because they fired briefly on the rising phase of the depolarization and then stopped firing during peak depolarization. In some of these cells firing resumed as the membrane potential decayed back to rest.

Intracellular injection of depolarizing current into sartorius motoneurons during motor activity reversed the direction of the membrane potential change from depolarizing to hyperpolarizing during the pause in sartorius discharge. In addition, the discharge evoked by the depolarizing current was blocked during the reversed part of the synaptic potential revealing its inhibitory nature. The occurrence of the IPSP was accompanied by a large reduction in motoneuronal input impedance. Injection of depolarizing current steps into motoneurons produced steady firing with no evidence of a pause in discharge, indicating that the depolarization accompanying synaptic activity was not responsible for the pause in firing of flexor motoneurons.

Received May 24, 1988; revised July 21, 1988; accepted July 22, 1988

This work was supported by the National Science Foundation (BNS 8402838) and by NIH (RO1 HD 23323). During part of this work the author was in receipt of an RCDA from NINCDS (KO4 NS 01246). Thanks are due to Matt Lee and Corey Cleland for their comments on draft versions of the manuscript.

Correspondence should be addressed to Michael J. O'Donovan, Laboratory of Neural Control, Room 5A-31, Bldg. 36, NINDS, NIH, Bethesda, MD 20892.

Copyright (C) 1989 Society for Neuroscience $0270-6474 / 89 / 030943-16 \$ 02.00 / 0$
These results suggest that flexor and extensor motoneurons receive a similar depolarizing drive from a common set of excitatory premotor interneurons. The alternating pattern of flexor and extensor discharge is produced, in part, by the timing of a depolarizing IPSP coincident with extensor activity that silences flexor discharge. The inhibition of motoneuron discharge that accompanies the IPSP appears to be mediated by a shunt conductance that prevents action potential generation.

Motor activity is believed to play an important role in the development of motoneurons and muscle (Renaud et al., 1978; Pittman and Oppenheim, 1979; Toutant et al., 1979; McLennan, 1983). In the chick, developmental changes in embryonic motility have been characterized in considerable detail (Provine, 1972, 1973; Ripley and Provine, 1972; Bekoff et al., 1975; Bekoff, 1976; Jacobson and Hollyday, 1982a, b), but much less is known about the cellular and synaptic mechanisms responsible for the generation of motor activity. This situation has arisen because of the obvious experimental difficulties associated with recording the firing pattern and synaptic drive of active motoneurons in ovo. Recently, an isolated preparation of the chick spinal cord has been developed that generates spontaneous episodes of motor activity in vitro (Velumian, 1981; Landmesser and O'Donovan, 1984; O'Donovan, 1987a). The pattern of hindlimb motoneuron activity produced by this preparation has been characterized previously using nerve and muscle recordings (Landmesser and O'Donovan, 1984; Barry and O'Donovan, 1987; O'Donovan and Landmesser, 1987). These studies have shown that each cycle of activity is initiated by a synchronous burst of spikes in most hindlimb muscles, similar to that recorded by Provine and his colleagues in ovo using microelectrode recordings from the spinal cord (Provine, 1972, 1973). Immediately after this initial burst, motoneurons stop firing and then fire a second burst of spikes later in the cycle. The duration of the pause in motoneuron firing is correlated with the function of the motoneurons during walking in the hatched chick (see Jacobson and Hollyday, 1982a, b). Motoneurons that are active in the swing phase of locomotion exhibit a long pause in each cycle. By contrast, extensor motoneurons that fire during the stance phase have a short or absent pause and stop firing earlier in the cycle than flexor motoneurons (see Landmesser and O'Donovan, 1984; Barry and O'Donovan, 1987; O'Donovan and Landmesser, 1987). These factors result in the coincidence of extensor discharge with the flexor pause leading to an alternating pattern of activity. The goal of the present work was to elucidate the cellular basis for this pattern of firing by recording the synaptic potentials in motoneurons during epi- 
sodes of motor activity. Preliminary accounts of some of this work have appeared in abstract form (O'Donovan, 1986) or have been discussed in reviews (O'Donovan, 1987a, b).

\section{Materials and Methods}

The excitatory drive responsible for motoneuron firing was analyzed using intracellular recording from individual lumbosacral motoneurons and DC-coupled recordings from ventral roots and muscle nerves. Intracellular recordings were obtained from 45 neurons located in the lateral motor column (LMC) of the anterior lumbar cord. Recordings were made between day 12 and 15 of embryonic development.

Isolated spinal cord preparation. All experiments were performed using an isolated preparation of the chick spinal cord (Landmesser and O'Donovan, 1984; O'Donovan, 1987a). The embryos were removed from the egg, rapidly decapitated, and pinned out in a Sylgard-lined dish that was continuously superfused with oxygenated $\left(95 \% \mathrm{O}_{2}, 5 \%\right.$ $\mathrm{CO}_{2}$ ) Tyrode solution at room temperature. The muscle nerves or ventral roots were dissected and the hemisected spinal cord removed from the vertebral column. Following this, all lumbosacral dorsal roots were cut. At the completion of the dissection the bath temperature was raised to $28-30^{\circ} \mathrm{C}$. After $3-5 \mathrm{hr}$ at the elevated temperature, spontaneous episodes of motor activity began that recurred every 5-10 min. Episodes of motor activity were also evoked by a single stimulus to the thoracic spinal cord (Landmesser and O'Donovan, 1984).

Spontaneous motor activity could be recorded from older embryos than previously reported in earlier work (Landmesser and O'Donovan, 1984). This was probably because the cord was completely isolated (see Barry and O'Donovan, 1987), which presumably resulted in better oxygenation of the neural tissue.

Intracellular recording from motoneurons. Intracellular recordings were obtained from motoneurons using glass microelectrodes filled with $2 \mathrm{M}$ potassium citrate or acetate and having impedances of 50-100 M $\Omega$ (O'Donovan, 1987a). The microelectrode was mounted on a motorized micromanipulator (Newport Corporation) and advanced into the spinal cord in small $(5 \mu \mathrm{m})$ steps. The bath and micromanipulators were mounted on a vibration-free table (Micro-G-Corporation) to maximize the stability of the preparation. The electrode was guided into the lateral part of the ventral cord until motoneurons were penetrated (see below). Recordings were made using conventional intracellular amplifiers (Getting or Axoclamp-2A) and stored on magnetic tape (Vetter model D) for subsequent analysis. Immediately after penetration it was usually necessary to stabilize the membrane potential by injecting hyperpolarizing current, which was eliminated as the membrane potential improved. The average membrane potential measured in 14 neurons was $-48 \mathrm{mV}$.

Motoneurons were identified by antidromic stimulation of the ventral roots or muscle nerves. In most experiments, anodal stimulation was used because this results in the largest extracellular antidromic field potentials when using metal microelectrodes (O'Donovan, 1987a). Highintensity cathodal stimulation reduced the amplitude of the extracellular field, probably due to anodal conduction block just outside the electrode tip (for further details, see Fig. 4 in O'Donovan, 1987a). Thresholds for antidromic activation were generally less than $50 \mu \mathrm{A} \mathrm{(50-150 \mu \textrm {sec } d u -}$ ration).

Forty-two of the 45 neurons that were recorded intracellularly were identified as motoneurons (see below). The 3 neurons that were not identified intracellularly were presumed to be motoneurons because of their location in the lateral motor column and their behavior during motor activity. Twenty of the motoneurons projected to muscle nerves (14 to the sartorius muscle nerve, 5 to the branch supplying one of the lateral heads of the femorotibialis muscle, and 1 to the obturator nerve), while the remainder were identified by ventral root stimulation.

Figure 1 illustrates the methods used for motoneuron identification. The illustration shows the all-or-none recruitment of an intracellular action potential during antidromic stimulation of the sartorius muscle nerve (Fig. 1 $A$ ). In this cell, the spontaneous occurrences of the action potential were followed one-for-one by a spike in the sartorius muscle nerve (Fig. $1 B$ ), confirming the antidromic identification. Of the 42 identified motoneurons, 35 were identified antidromically and the remaining 7 by the occurrence of a one-for-one spike in the muscle nerve.

In most motoneurons antidromic stimulation resulted in an all-ornone spike without any subthreshold potential changes. Occasionally, however, antidromic stimulation recruited a small potential at stimulus currents lower than the threshold for the antidromic spike (see Fig. 1C).
These potentials were unlikely to be synaptic because the dorsal roots were cut. Although the properties of the potentials were not thoroughly investigated, they resembled small action potentials and consisted of a small spike and a prolonged afterhyperpolarization (see Fig. $1, C, D$ ). The potentials were insensitive to membrane polarization $(n=1)$, could occur spontaneously, and were sometimes followed, one-for-one, by a spike in the muscle nerve. They were most commonly seen immediately after penetration and may have been associated with cell damage, although they could sometimes persist in what appeared to be a satisfactory penetration. One interpretation of these data is that the small spikes arose from a depolarized or damaged initial segment, although it is difficult to explain why their stimulus threshold should be different from the antidromic spike. An alternative possibility is that the small spikes arise as a result of electrical coupling between adjacent motoneurons.

Current spread during muscle nerve and ventral root stimulation. Several precautions were taken to minimize current spread during antidromic stimulation of muscle nerves. In some experiments, only the sartorius nerve was used and all other nerves were cut. In experiments where the lateral branch of the femorotibialis muscle was also dissected, the other nerve branches were stripped back proximally and then cut. With either arrangement, stimulus spread rarely occurred. When it did, it was manifest by short-latency compound action potentials in the nonstimulated nerve and could be eliminated by repositioning the stimulating electrode more distally along the nerve.

Stimulus spread was also a concern with ventral root stimulation because of the possibility that motoneurons (or interneurons) might be directly activated by current spread to the lateral motor column rather than antidromically. However, direct activation of spinal neurons by ventral root stimulation is unlikely for 2 reasons. First, direct stimulation of the spinal cord elicited burst activity in motoneurons, which was very rare following ventral root stimulation. Second, in most motoneurons (14/22), the antidromic spike occurred after a significant delay $(>1 \mathrm{msec})$ following the ventral root stimulus, and in only one neuron was the latency short enough $(<0.5 \mathrm{msec})$ to be compatible with direct activation.

Ventral root and muscle nerve recordings. Recordings of neural activity were made from muscle nerves or the ventral roots using a tightly fitting suction electrode connected to a high-gain DC amplifier (Grass P16; $\times 1000$ gain) via a chlorided pellet. The recordings were made with a wide bandwidth (DC-5 kHz), which allowed slow potentials and propagated spike activity to be resolved (O'Donovan, 1987a). Recordings were stored on magnetic tape for subsequent analysis. Slow positive potentials recorded in this manner appear to be similar to the electrotonically decremented population synaptic potentials that can be recorded from the cut ventral roots of adult animals (Luscher et al., 1979; Brink et al., 1983). Success in achieving these recordings presumably results from the short length $(2-3 \mathrm{~mm})$ of the cut muscle nerves in the embryo. Despite the short nerves, the attenuation of the intracellularly recorded potentials was significant and can be approximated by comparing the aggregate synaptic potential generated in a population of motoneurons with the amplitude of the slow potentials recorded from the muscle nerve. In the present work, the average intracellularly recorded motoneuron depolarization was $15 \mathrm{mV}$ (see text), which would correspond to an aggregate depolarization of $6 \mathrm{~V}(15 \mathrm{mV} \times 400)$ for the 400 motoneurons supplying the sartorius muscle (Landmesser, 1978). Since the slow potentials recorded from the sartorius nerve were typically between 100 and $200 \mu \mathrm{V}$, this would result in an attenuation ranging from 30,000 to 60,000 . The actual electrotonic decay will probably be less than this because the extracellularly recorded slow potentials are necessarily smaller than the intra-axonal potential at the end of the muscle nerve. Nonetheless, these attenuation factors are compatible with what is probably a short space constant in the small unmyelinated motor axons in the muscle nerve.

This type of recording complements the intracellular records by providing an independent monitor of the membrane events in a defined population of motoneurons. Moreover, the recordings are easy to obtain and are without the complications resulting from the intracellular penetration of small motoneurons (see below and Velumian, 1984). Although population potentials average the activity of a large number of motoneurons, intracellular recording has revealed that they provide a reasonable monitor of the transmembrane potential trajectory in individual motoneurons (O'Donovan, 1987a; see also data in this paper).

Data analysis. The time course of intracellular membrane potential changes and muscle nerve potentials was summarized by combining the results of many cycles of activity from several different experiments. 

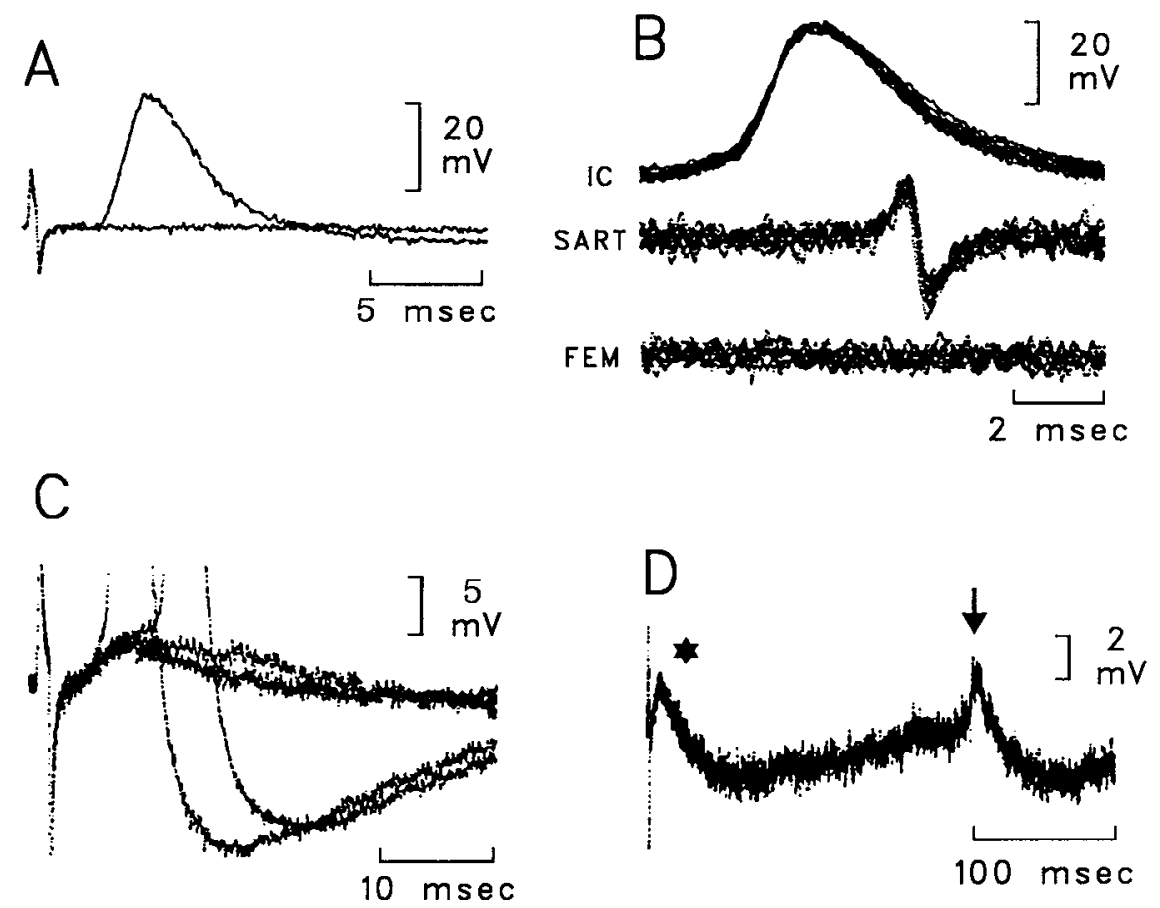

Figure 1. Identification of sartorius motoneurons recorded intracellularly. $A$, All-or-none recruitment of a shortlatency action potential following antidromic stimulation of the sartorius muscle nerve. In this motoneuron, the intracellular spike was correlated onefor-one with a spike in the sartorius muscle nerve (shown in $B$ ). $B$, Superimposition of several sweeps of the spontaneous spike $(I C)$ together with the sartorius (SART) and femorotibialis $(F E M)$ ncurograms. $C$, Antidromic stimulation of another sartorius motoneuron revealed a small potential evoked at a lower stimulus intensity than the larger antidromic spike. $D$, The small potential could be antidromically activated alone (starred) and was also spontaneously active (arrowed). Recordings were made from a 14-d-old embryo in which all the lumbosacral dorsal roots had been cut.
For this purpose the intracellular records from 9 sartorius and 4 femorotibialis motoneurons and their accompanying wideband nerve records were used. A similar analysis was used to summarize the results of depolarizing current injection in 3 sartorius motoneurons. The wideband nerve records were first processed to separate the spike activity and the slow potentials. The spike activity was filtered at a bandwidth of $100 \mathrm{~Hz}-5 \mathrm{kHz}$ and then rectified and integrated (time constant, 20 msec), whercas the slow potentials were filtered at DC-20 Hz. Slow potentials filtered in this way were very similar in time course to the original unfiltered slow potential, although some distortion was inevitably introduced due to integration of the spike activity (see also Fig. 1, O'Donovan and Landmesser, 1987). This procedure resulted in either 3 or 5 simultaneously recorded channels of data for further processing depending on whether both the sartorius and the femorotibialis neurograms were recorded initially. These were (1) intracellular membrane potential from a sartorius or a femorotibialis motoneuron; (2) integrated sartorius nerve discharge; (3) integrated femorotibialis nerve discharge; (4) slow sartorius nerve potentials; and (5) slow femorotibialis nerve potentials. The intracellularly recorded membrane potential and the integrated nerve activity were also filtered between $\mathrm{DC}$ and $20 \mathrm{~Hz}$ so that all available data channels were subjected to the same filtering conditions. Intraccllular rccords werc sclected in which spike activity was rare or had been suppressed by injection of hyperpolarizing current, although some of the records did contain spikes. All channels of data were then digitized at $50 \mathrm{~Hz}$ for computer analysis. Some of the intracellular records (particularly during current injection) and occasionally the DC nerve records were subject to drift, which was corrected by computing the slope of the drift and subtracting it from the record. All records were then normalized by amplitude.

The subsequent processing consisted of 2 stages. First, the intracellular activity and nerve records were averaged over several episodes for individual motoneurons. Second, these averages were combined for all the motoneurons in each group ( 9 sartorius, 4 femorotibialis, 3 depolarized sartorius).

Averages could not be generated from complete episodes because of variability in the duration and structure of successive episodes. For this reason, each episode was first separated into its constituent cycles, which were then averaged as described in Figure 2. Cycle lengths were not normalized because cycle parameters (e.g., pause duration) tend to be constant and independent of cycle length (see Landmesser and O'Donovan, 1984; O'Donovan and Landmesser, 1987). This procedure was implemented for all available data channels and resulted in the compression of a complex episode (Fig. $2 A$ ) into a much simpler single cycle average (Fig. $2 C$ ). Single cycle averages were generated from several episodes and then averaged together.
Finally, the single cycle averages for all the motoneurons in each group ( 9 sartorius, 4 femorotibialis, 3 depolarized sartorius) were normalized and averaged together.

\section{Results}

Slow potentials and spike activity recorded from flexor and extensor muscle nerves

Figure 3 illustrates recordings from the flexor sartorius and the extensor femorotibialis muscle nerves during an episode of motor activity in a 13-d-old embryo. In both muscle nerves spike activity was superimposed on a slow positive potential. The pattern of discharge exhibited by these motoneurons was most evident when individual cycles could be seen in isolation towards the end of an episode. As reported previously (Landmesser and O'Donovan, 1984; Barry and O'Donovan, 1987) and confirmed in the present report, both sets of motoneurons discharge at the beginning of the cycle during the synchronous discharge (labeled in Fig. $3 B$ ). Sartorius motoneurons stop firing after the synchronous discharge and then resume again later in the cycle. The firing of femorotibialis, and other extensor motoneurons, persists during the pause in sartorius discharge which produces an alternating pattern of activity (Figs. 3B, 4, upper traces).

Remarkably, however, the slow population potentials were similar, and coincident, in both muscle nerves. Femorotibialis motoneurons fired during the peak of the slow population potential, whereas sartorius motoneurons stopped firing at this time and resumed their discharge as the population potential decayed (see Figs. 3 and 4). Similar findings were obtained in 7 experiments and with other flexor and extensor nerves (e.g., medial femorotibialis and posterior iliotibialis).

In embryos $13 \mathrm{~d}$ and older, the pause in each cycle of sartorius activity was briefer and femorotibialis activity was more prolonged than at younger stages. In addition, the timing of successive cycles was irregular with double or even triple bursts occurring rapidly in succession. This resulted in coactivation of sartorius and femorotibialis discharge in some cycles. Such coac- 


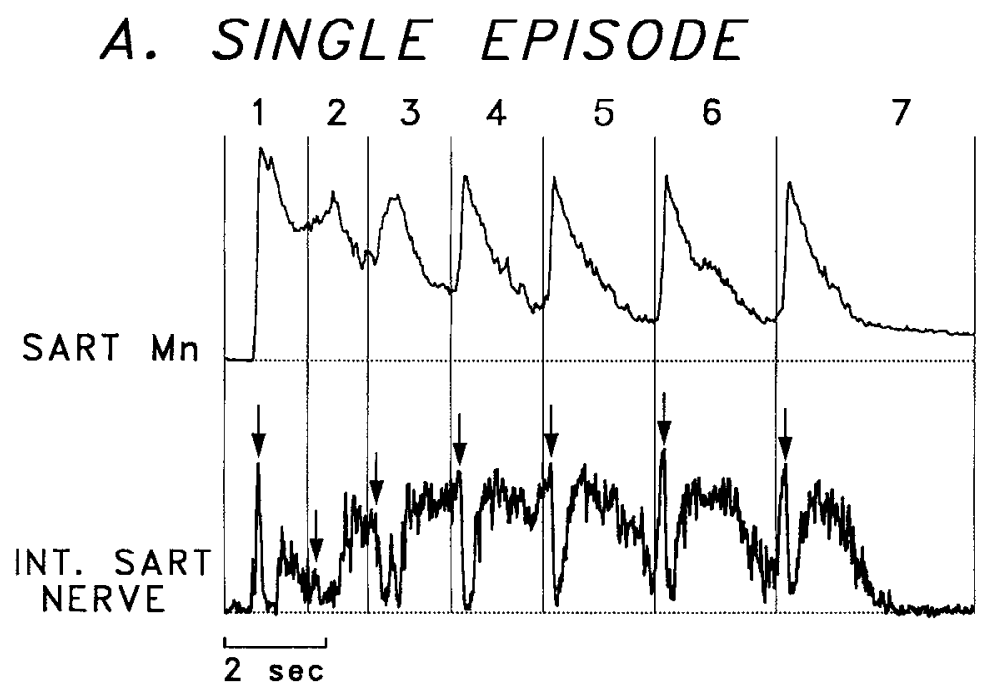

Figure 2. Method used to average all the cycles in a single episode of motor activity. $A$, Simultaneous recordings of intracellular membrane potential from a sartorius motoneuron ( $S A R T M n)$ and rectified, integrated neural activity from the sartorius muscle nerve (INT. SART $N E R V E$ ). The time of occurrence of the peak in the sartorius synchronous discharge or the onset of the pause (if the synchronous discharge was not discernible) was identified in each cycle. These trigger points are indicated by arrows on the nerve trace. The episode was then divided into cycles, each of which extended from $200 \mathrm{msec}$ prior to a trigger point to $200 \mathrm{msec}$ prior to the next trigger. The cycles are numbered and delineated by fine lines in the intracellular and nerve traces. $B$, Superimposition of individual cycles from the intracellular record shown in $A$. Each trace is aligned at the trigger point. Note that the length of each segment varies. $C$, Average of the superimposed traces shown in $B$. Note that the number of cycles contributing to each section of the average varies. At the trigger point, all 7 cycles contribute to the average, whereas at the end of the cycle only a single cycle (7) is used.

\section{B. SUPERIMPOSE CYCLES}
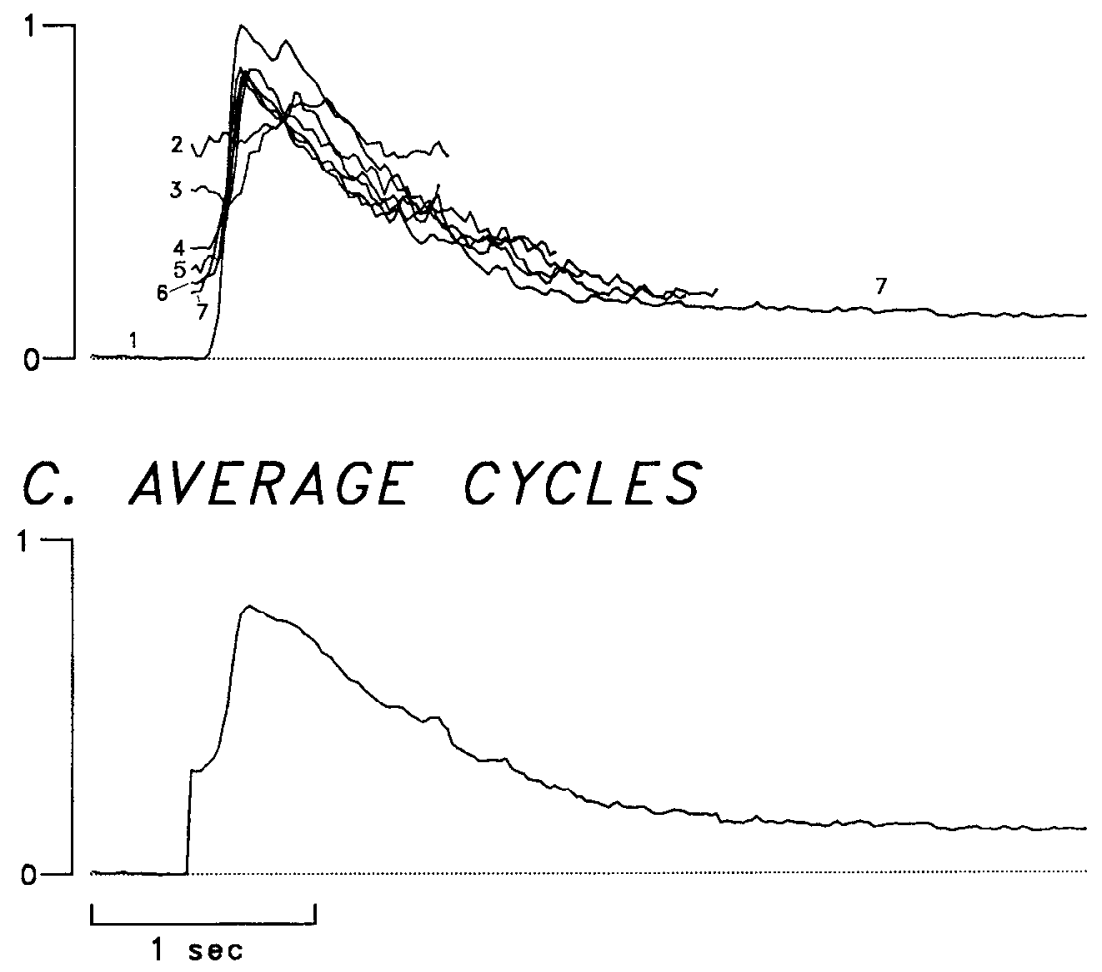

tivation was rare before $13 \mathrm{~d}$ except at the beginning of an episode, when cycles recurred rapidly (see Landmesser and O'Donovan, 1984). At all ages, however, the slow population potentials were in phase. Figure 4 illustrates these observations by comparing an episode of motor activity in a 12- and a 13-dold embryo.

The reasons for this change in the precision of alternation in the embryos $13 \mathrm{~d}$ and older is unclear. However, a similar change in the phasing of flexor and extensor hindlimb muscle activity has been observed in ovo at about the same stage of development. Bekoff (1976) found that hindlimb EMG activity became disorganized at day 13 with complex burst patterns and frequent periods of coactivation between the antagonists gas- trocnemius and tibialis anterior-muscles that exhibit alternating activity at earlier stages of development.

The similarity of the population potentials in the 2 nerves raised the possibility that the excitatory synaptic drive to the 2 sets of motoneurons was also similar and in phase. This hypothesis was tested by intracellular recording from identified motoneurons during motor activity as described bclow.

\section{Intracellular recordings from motoneurons during motor activity}

Intracellular recordings were obtained from 42 motoneurons (and 3 additional lateral motor column neurons presumed to be motoneurons) during episodes of motor activity. Immedi- 


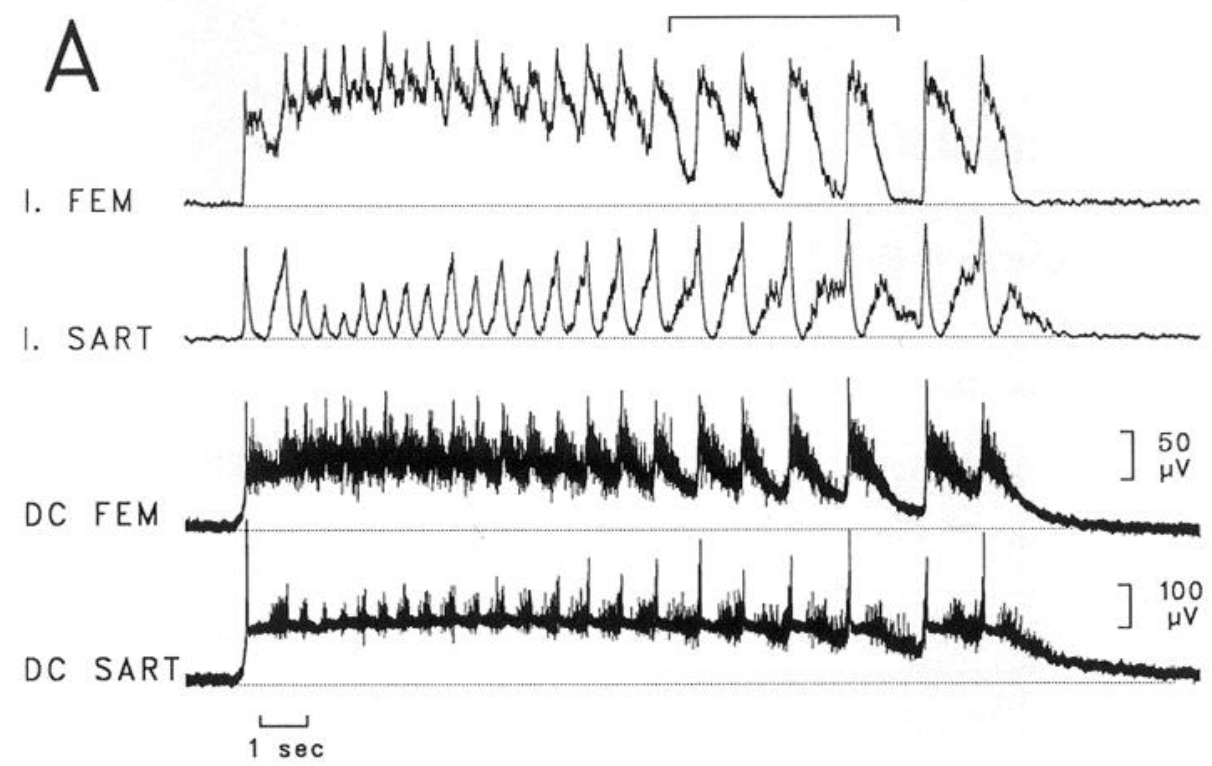

B

I. FEM

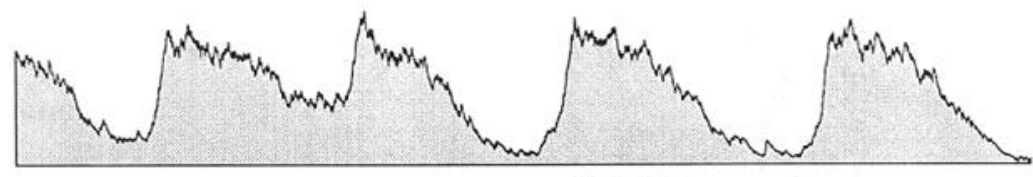

PAUSE

I. SART

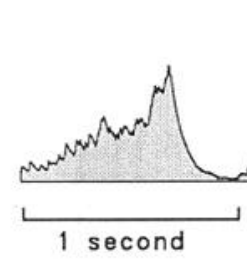

Figure 3. A, Wideband recordings from the sartorius and femorotibialis muscle nerves (traces marked $D C$ ) during an episode of motor activity reveal slow population potentials on which propagated spike activity is superimposed. The pattern of discharge can be seen more clearly after high-pass filtering, rectifying and integrating the wideband record as shown in the upper traces (labeled I. FEM and I. SART). The extensor spike activity in the DC record was reduced by filtering (DC$200 \mathrm{~Hz}$ ) to show the profile of the underlying slow potential more clearly. $B$, Expanded portion of the integrated nerve discharge (identified by the line in the upper trace of $A$ ) to show the phasing of activity between the 2 antagonist muscle nerves, and identifying the components of each cycle of activity. $S Y N C$, synchronous discharge; $P A U S E$, interruption in sartorius discharge. ately following penetration, motoneurons fired irregularly or at a low rate. As the penetration was maintained, the membrane potential improved, and most cells began to fire reproducibly during each cycle of activity. Satisfactory penetrations of a few motoneurons could be maintained for $1-2 \mathrm{hr}$, during which time the stabilized firing pattern of the cell changed little. Several motoneurons did not discharge at all during motor activity, even though they received depolarizing synaptic drive and may have been damaged by the penetration.

For 14 sartorius motoneurons the latency of the antidromic spike (or the time from the intracellular spike to the orthodromic spike in the muscle nerve) averaged $3.9 \pm 1.6 \mathrm{msec}$ (mean \pm SD), which corresponds to a conduction velocity of $\simeq 0.5$ $\mathrm{m} / \mathrm{sec}$, assuming a conduction distance of about $2 \mathrm{~mm}$. The latency of antidromic spikes was much shorter following ventral root stimulation $(1.2 \pm 0.6 \mathrm{msec} ; n=22)$. The conduction velocity of individual motoneurons was not calculated because of uncertainties in its estimation. The mean amplitude of the action potential for motoneurons included in the study was 45.5 $\pm 18.3 \mathrm{mV}(n=41)$.

The intracellular recordings confirmed the nerve recordings and revealed that motoneurons were depolarized during each cycle of activity, on average by $14.9 \pm 9.8 \mathrm{mV}$ [range, 1.1-34.9 $\mathrm{mV}(n=39)]$. The depolarization rose rapidly at the onset of each cycle and decayed near the end of the cycle, although in some neurons temporal summation of successive cycles resulted in a sustained depolarization.

Figure 5 illustrates an intracellular recording from a femorotibialis motoneuron together with a recording from the femorotibialis muscle nerve, revealing that the slow population potentials coincide with the depolarization in individual femorotibialis motoneurons. The intracellularly recorded potential is generated exclusively by transmembrane potential changes because virtually no extracellular field potential was recorded when the electrode was withdrawn from the cell (EC control in Fig. 5B). Indeed, in no cell tested (15/15) was a significant extracellular field potential recorded on withdrawing the microelectrode from the cell. Similar transmembrane potential changes were recorded in 3 of the remaining femorotibialis motoneurons and several additional ventral root identified motoneurons presumed to be extensors on the basis of their firing pattern. In these cells the membrane potential depolarized at cycle onset, reaching a plateau for a portion of the cycle before decaying at the end of the cycle. Motoneuron discharge occurred at the peak of the depolarization and stopped as the depolarization decayed back to rest. This pattern of discharge was also reflected in the population recordings from the femorotibialis nerve because the propagated spike activity occurred during the 
Figure 4. Comparison of burst activity in 12- and 13-d-old embryos. The lower records in each set (labeled $D C$ ) are wideband recordings comparing activity in the sartorius $(S A R T(D C))$ and femorotibialis $(F E M(D C))$ muscle nerves. The pattern of discharge between the antagonist nerves can be seen after high-pass-filtering the wideband data $(100 \mathrm{~Hz}-1.5$ or $5 \mathrm{kHz})$, as shown in the upper set of records in each set (labeled $A C$ ). Note the more precise pattern of alternating discharge in the $12 \mathrm{~d}$ embryo, although the slow potentials occur at the same time in each muscle nerve at both ages. At day 13 the slow potentials occur simultaneously in both muscle nerves whether the discharge alternates (starred cycle) or is coincident (arrowed cycle). The temorotibialis spike activity in the $\mathrm{DC}$ record from the $12 \mathrm{~d}$ embryo was reduced by filtering $(\mathrm{DC}-100 \mathrm{~Hz})$ to reveal the profile of the underlying slow potential.
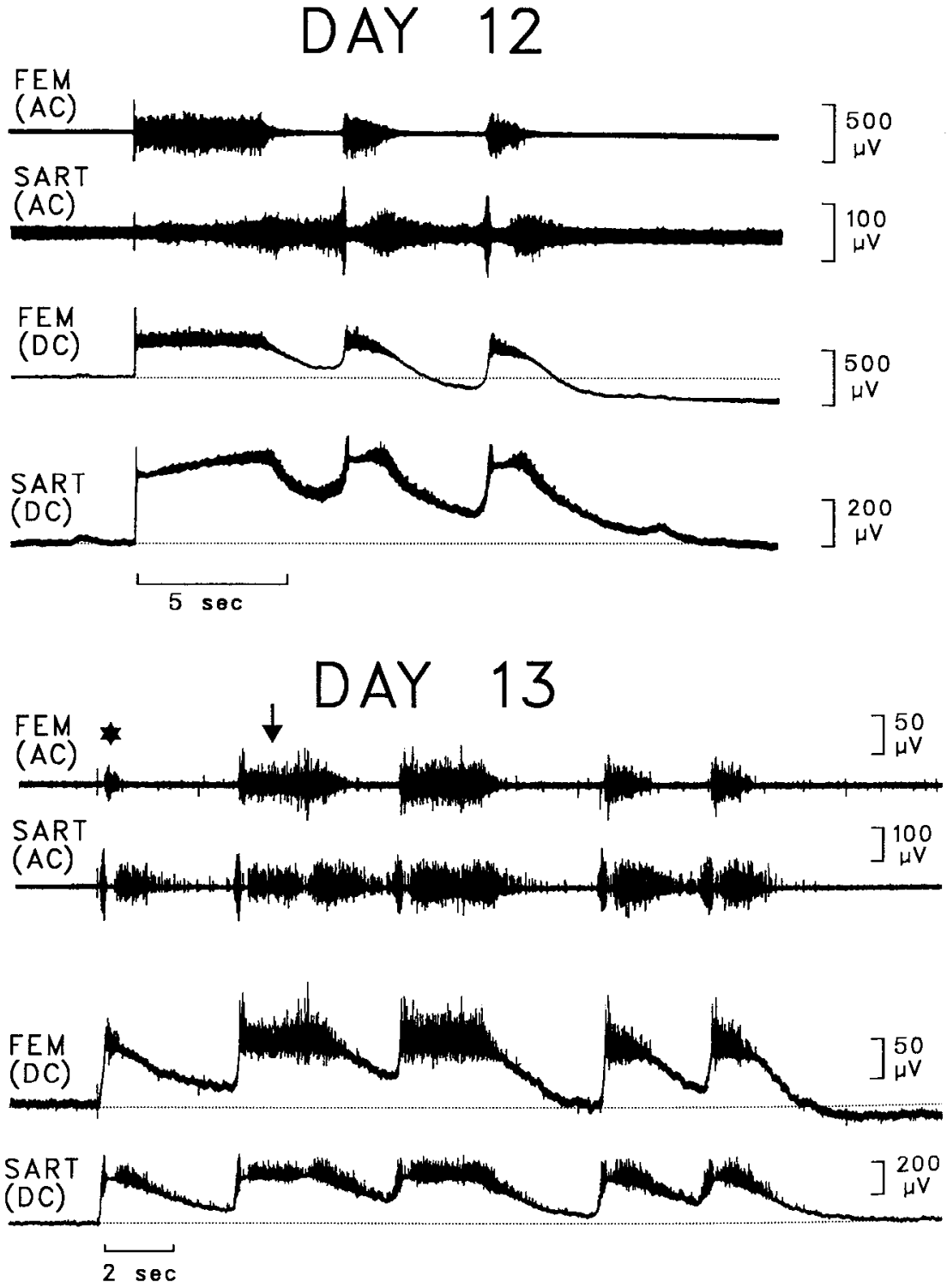

peak and plateau phase of the slow potential (Fig. 5). In 2 femorotibialis motoneurons the intracellular potential decayed to rest significantly faster than the nerve potential (reflected in the averages of Fig. 7). One of the antidromically identified femorotibialis was held only briefly and was sufficiently depolarized to fire continuously. During burst activity, the depolarization was not marked in this cell and a brief hyperpolarization occurred at cycle onset (see further discussion below).

Intracellular recordings from sartorius motoneurons revealed a similar correspondence between transmembrane potential changes in individual cells and population recordings from the muscle nerves (illustrated in Fig. 6 and summarized in Fig. 7) and confirmcd that sartorius motoneurons were depolarized during each cycle of motor activity and remain depolarized during the pause in nerve discharge (Fig. $6 \mathrm{~A}$ ). In several sartorius motoneurons a prominent depolarizing bump occurred in the intracellular record (starred in Fig. 6A) at the time of the pause in the sartorius nerve discharge, although in other sartorius cells (e.g., neuron illustrated in Fig. $8 A$ ), the membrane potential remained flat during the pause in discharge. In sartorius motoneurons, as in other motoneurons, no extracellular fields could be recorded on withdrawing the electrode to just outside the cell (Fig. 6B).

The above results show that the intracellular membrane potential changes in both sartorius and femorotibialis motoneurons coincide with the slow potentials in their muscle nerves. Since the slow potentials in the flexor and extensor muscle nerves are also coincident, this implies that the intracellular membrane potential changes in flexor and extensor motoneurons occur at the same time also. Although it was not possible to obtain simultaneous intracellular recordings from sartorius and femorotibialis motoneurons, the relative timing of their intracellular activity could be compared by using the simultaneously recorded nerve potentials as a reference.

This has been done in Figure 7, which documents the relationships between intracellularly recorded membrane potential in sartorius and femorotibialis motoneurons and the corresponding recordings from the muscle nerves during a single cycle of activity (see Materials and Methods and legends to Figs. 2 and 7 for further details). Figure 7 consists of 2 sets of single cycle data: averages from 9 sartorius motoneurons and the accompanying nerve records (indicated by the thick traces) and a 

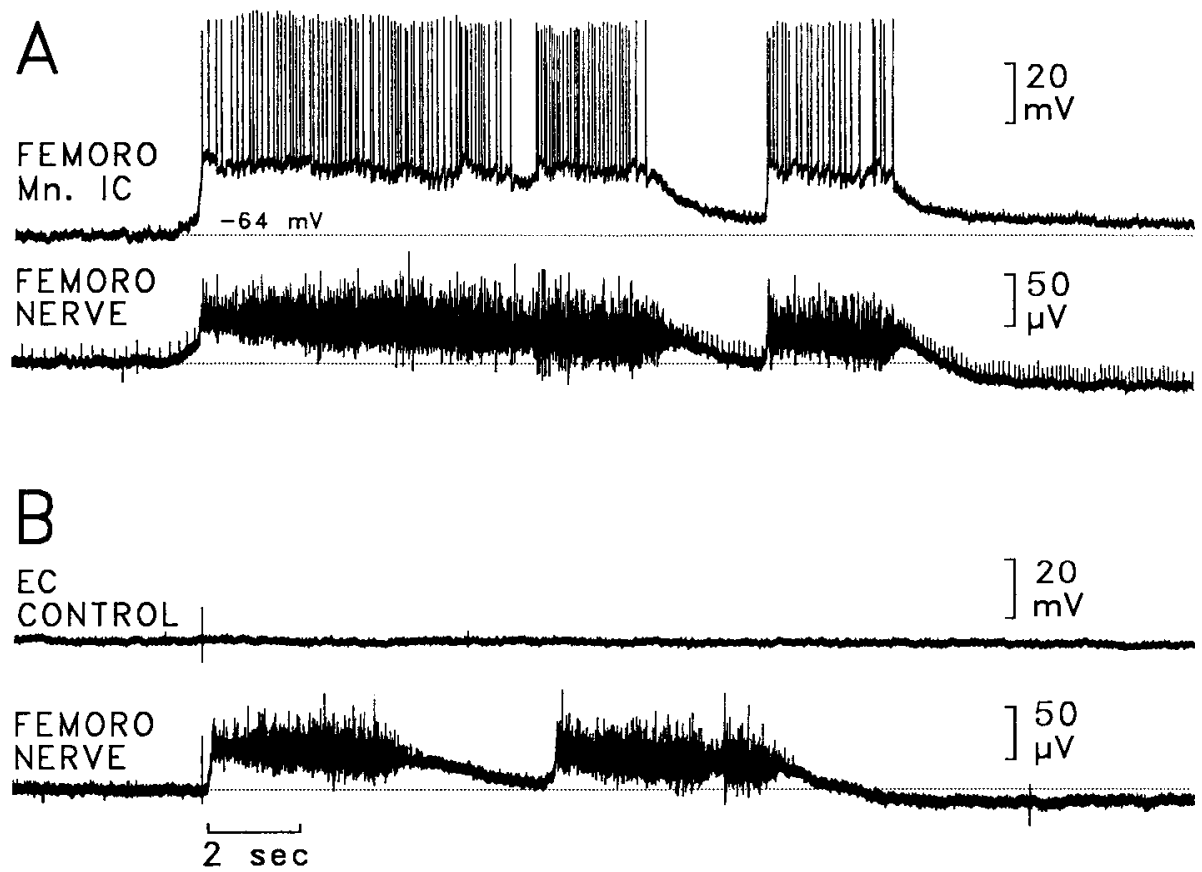

Figure 5. $A$, Intracellular recording from a femorotibialis motoneuron during a spontaneous episode of motor activity in a $13 \mathrm{~d}$ embryo. The upper trace (FEMORO Mn. IC) is the intracellular record and the lower trace the DC record from the muscle nerve (FEMORO $N E R V E$ ). The membrane potential just before the onset of the burst is shown. $B$, Recording of the extracellular field potential just outside the motoneuron ( $E C$ CONTROL) during an episode of motor activity reveals that the intracellularly recorded potential changes arc transmembrane.

second set of data averaged from 4 femorotibialis motoneurons and their accompanying nerve records (thin traces). The 2 sets of traces have been synchronized at the peak of the synchronous discharge in the sartorius nerve so that they are aligned at the same point in the cycle. The average cycle length is the same for each set of records because the duration of nerve activity is the same for both data sets (compare duration of thick and thin lines for each nerve record in Fig. 7). For this reason the intra-
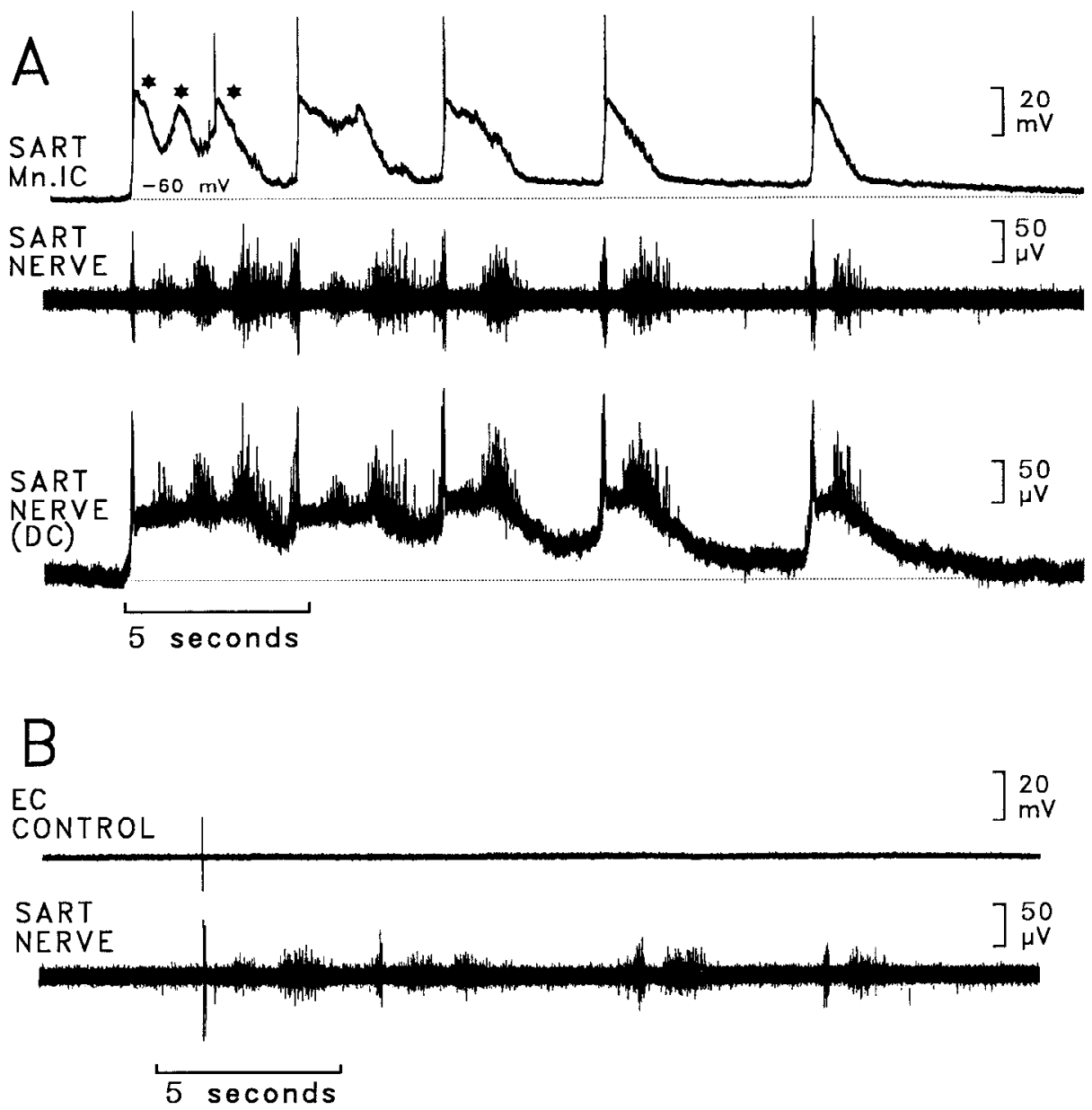

Figure 6. $A$, Intracellular recording from a sartorius motoneuron during an episode of motor activity. The intracellular record (SART Mn. IC) is shown together with a $D C$ recording of population activity in the sartorius muscle nerve (SART NERVE DC), and the propagated spike activity in the sartorius nerve (SART NERVE) obtained by high-pass-filtering the $\mathrm{DC}$ record $(100 \mathrm{~Hz}-5 \mathrm{kHz})$. Note the prominent depolarizing bumps (starred) that coincide with the pause in firing in the sartorius muscle nerve. $B$, Extracellular recording of the potential just outside the motoneuron during another episode of motor activity (EC CONTROL). 
Figure 7. Averaged responses of normalized muscle nerve and motoneuron behavior during a single cycle of motor activity (see Materials and Methods for details). The figure consists of 2 sets of single cycle data: intracellular averages compiled from 9 sartorius motoneurons together with simultaneous sartorius and femorotibialis nerve records (indicated by the thick traces) and a second set from 4 femorotibialis motoneurons and their associated nerve records (thin traces). The 2 sets of traces are aligned at the peak of the synchronous discharge in the sartorius nerve. The intracellular records are shown as the mean membrane potential \pm 1 intercell SD (shaded region). The muscle nerve recordings show the slow population potentials (labeled $D C$; filtered at $\mathrm{DC}-20 \mathrm{~Hz}$ ) together with the rectified integrated neural activity (Int.).

Figure 8. $A$, Intracellular recording from a sartorius motoneuron that fired during several cycles of an episode (SART Mn IC). Also displayed is the instantaneous frequency of firing of the cell (INST FREQ). Notice that the membrane potential plateaus throughout the episode and that firing occurs as the membrane potential decays at the end of each cycle. $B$, Intracellular recording from another motoneuron that exhibited similar behavior to the cell illustrated in $A$. In this case, the motoneuron, which was identified by ventral root $(L S I)$ stimulation, also displayed a long pause in each cycle, during which the membrane potential remained flat. Moreover, the intracellular membrane potential recorded during motor activity was very similar to the simultaneously recorded ventral root potential, suggesting that the membrane potential changes were not significantly altered by the presence of the intracellular electrode.
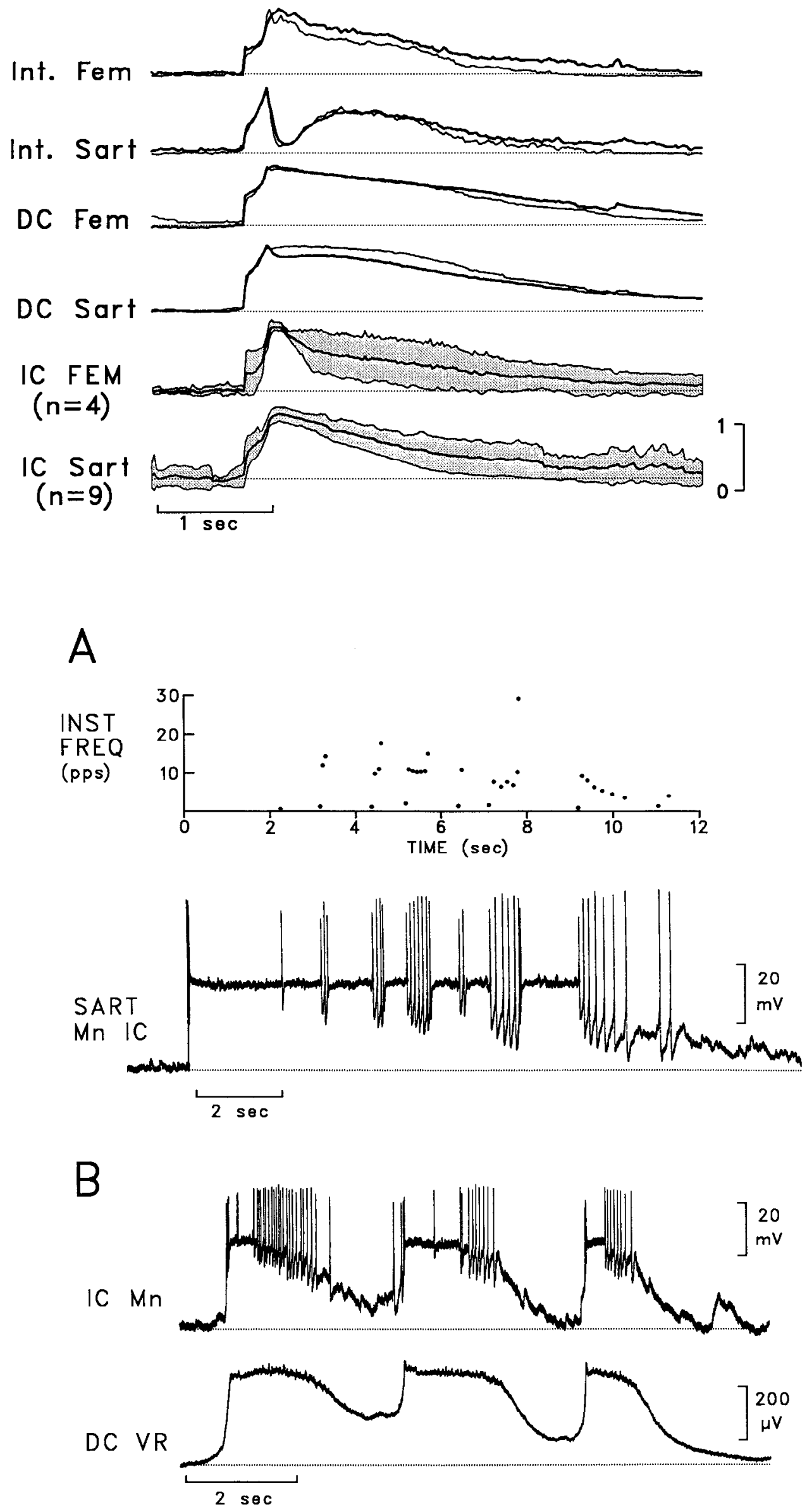

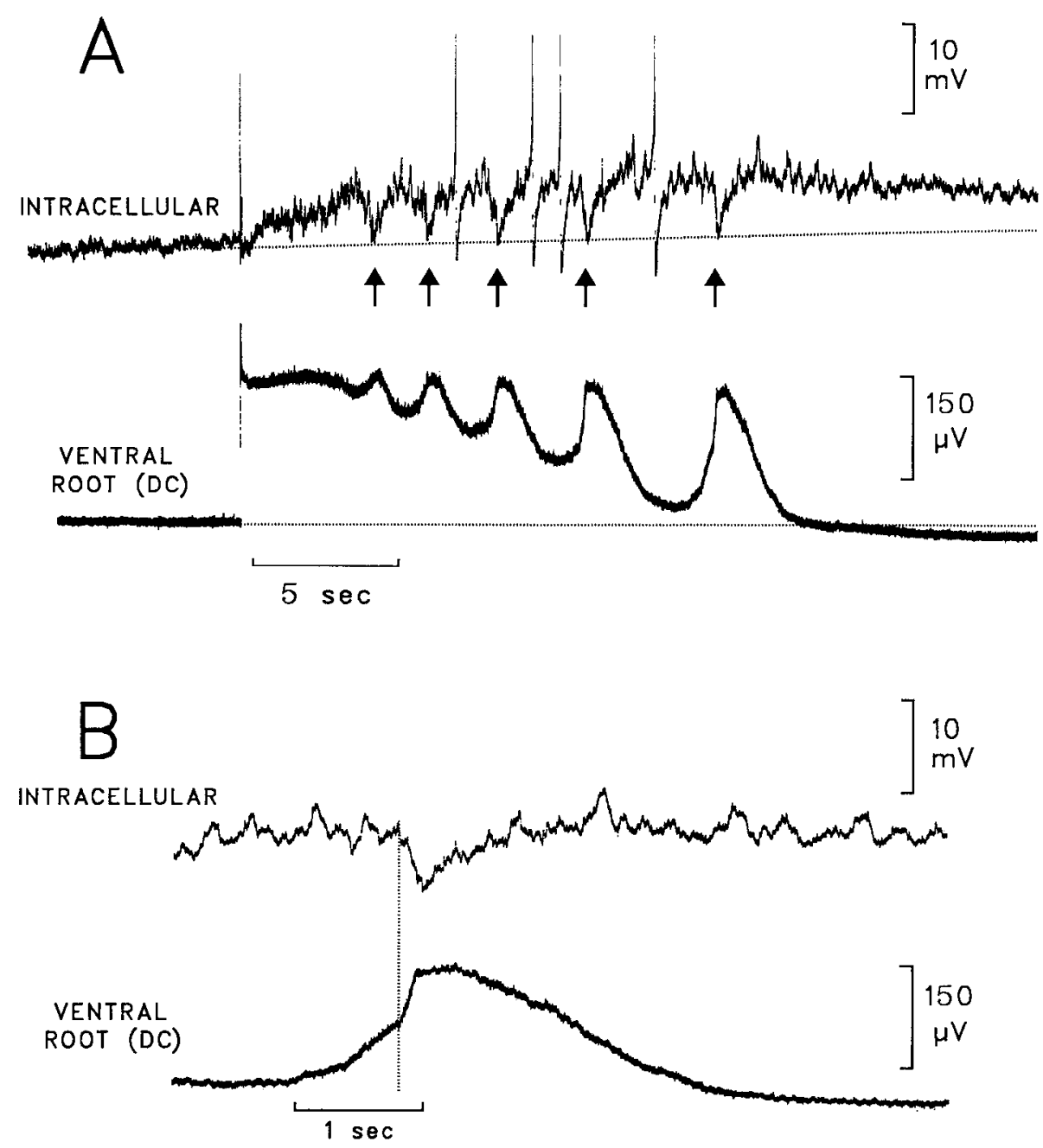

Figure 9. $A$, An example of a ventral root identified motoneuron (INTRACELLULAR) that exhibited hyperpolarizing potentials (arrowed) superimposed on a depolarization. The record was obtained shortly after penetration while the membrane potential was drifting. $B$, The last cycle shown on an expanded time scale to show the distinct depolarizing peak in the ventral root record (VENTRAL ROOT (DC)) that coincides with the hyperpolarizing potential in the motoneuron. The depolarizing ventral root response, although from a population of motoneurons, suggests that the IPSP is actually depolarizing in unpenetrated motoneurons (see text for further discussion). Spikes in $A$ are not displayed at full amplitude. cellular averages from the sartorius and femorotibialis motoneurons can be compared on the same time scale. Figure 7 clearly reveals that the averaged intracellular activity in sartorius and femorotibialis motoneurons is both coincident and similar, although the membrane potential in femorotibialis motoneurons decays somewhat faster than that in the sartorius neurons. The low intercell SD in the sartorius record reflects the fact that the intracellular potentials in most of the individual sartorius motoneurons were similar.

These data also allow a comparison of the time course of the averaged nerve activity and the intracellular records during a single cycle. The slow potentials from the sartorius and femorotibialis muscle nerves were similar, as discussed earlier. Comparison with the averaged intracellular records showed that the basic form of the slow potentials was similar to the corresponding intracellular records, which was expected since the slow nerve potentials reflect synaptic activity in a population of motoneurons. Despite the fundamental similarity between the DC nerve and intracellular records, some differences were apparent. For instance, the DC nerve records decayed more slowly than the intracellular records, presumably because of electrotonic slowing along the muscle nerve, and probably also due to the presence of integrated spike activity introduced by the low-pass filtering (DC-20 Hz). Integration of spike activity is probably also responsible for the small peak in the DC sartorius record at the time of the synchronous discharge that has no counterpart in the intracellular records.

Burst activity was recorded from an additional 22 motoneurons that were identified from the ventral roots. The great majority of these motoneurons were depolarized during each cycle of activity in a manner similar to that described for sartorius and femorotibialis motoneurons. In many cells, the time course of the depolarization was similar to that recorded simultaneously from the ventral roots (see Fig. $8 B$ ), although in some the intracellularly recorded potential was briefer than the ventral root potential. At face value, the similarity of the ventral root potential and membrane potential changes in individual motoneurons was surprising because ventral root potentials are generated from synaptic activity in an heterogeneous population of flexor and extensor motoneurons. However, in the preceding section it has been shown that the flexor sartorius and the extensor femorotibialis receive coincident and similar synaptic drive during motor activity. Similar observations were made in other flexors and extensors using muscle nerve recordings, suggesting that all the hindlimb motoneurons experience a fundamentally similar depolarization during motor activity. If the major synaptic drive to different motoneurons is fundamentally similar, then the ventral root potential will be a useful monitor of the membrane potential trajectory in motoneurons unpenetrated by microelectrodes, although caution must be exercised 


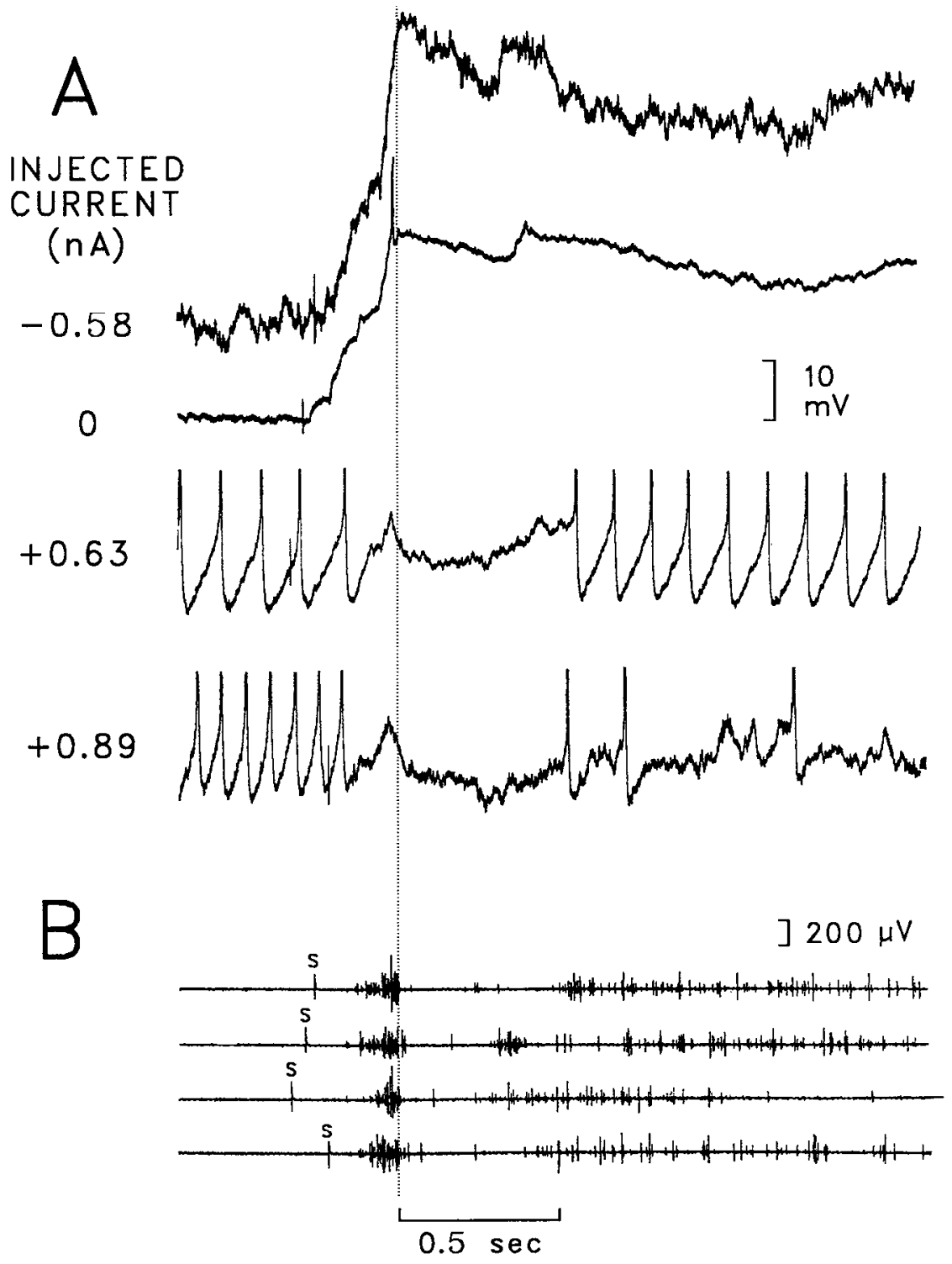

Figure 10. $A$, Effects of intracellular current injection on the motor depolarization generated in a sartorius motoneuron. The 4 traces are intracellular recordings of the first cycle of activity in a burst episode recorded at different levels of injected current (shown to the left of the traces). $B$, The 4 traces are the sartorius neurograms associated with each of the 4 intracellular records shown in $A$. All traces have been aligned at the start of the pause recorded in the sartorius neurogram (indicated by the dotted line). Each episode was initiated by a single stimulus to the thoracic cord (stimulus artifact marked by $S$ ). Spikes in $A$ are not displayed at full amplitude.

when inferring single-cell behavior from population recordings. One advantage of ventral root recording over muscle nerve recording is that ventral root potentials are less distorted electrotonically than muscle nerve recordings and spike activity tends to be less pronounced (see also Fig. 1 in O'Donovan and Landmesser, 1987).

\section{Firing pattern of individual flexor motoneurons}

About half of the sartorius motoneurons that were recorded from discharged infrequently or primarily on the rising phase of the depolarization, coincident with the synchronous discharge in the muscle nerve. Other sartorius motoncurons (and ventral root identified motoneurons that behaved like flexors), fired 2 bursts of spikes in each cycle resembling the discharge pattern recorded in the muscle nerve. Two such motoneurons are illustrated in Figure 8. One of these motoneurons projected to the sartorius muscle nerve, while the other was identified as originating from the LS1 segment, where sartorius motoneurons are located. In both cells the membrane potential depolarized to a plateau of 25-30 mV during each cycle. Firing occurred on the rising phase of the depolarization and then ceased as the membrane potential plateaued, resuming as the membrane potential decayed from its peak level. These observations indicate that firing in sartorius motoneurons could be silenced even though the membrane potential was above threshold for spiking.

Several possible mechanisms could contribute to the silencing of discharge in sartorius motoneurons, including synaptic inhibition and voltage-sensitive membrane properties. A role for synaptic inhibition was suggested by the observation that a few motoneurons (7/45), including one femorotibialis motoneuron, exhibited small negative deflections of membrane potential (supcrimposed on the depolarization) that occurred just after the onset of each cycle coincident with the pause in flexor firing (see Fig. 9). The negative deflections were most common when the membrane was somewhat depolarized immediately after penetration and attenuated or reversed as the penetration persisted. These findings raised the possibility that the pause in flexor firing might be mediated by an inhibitory postsynaptic potential. This was investigated by injecting current into several sartorius motoneurons in an attempt to reverse the hypothesized IPSP. 


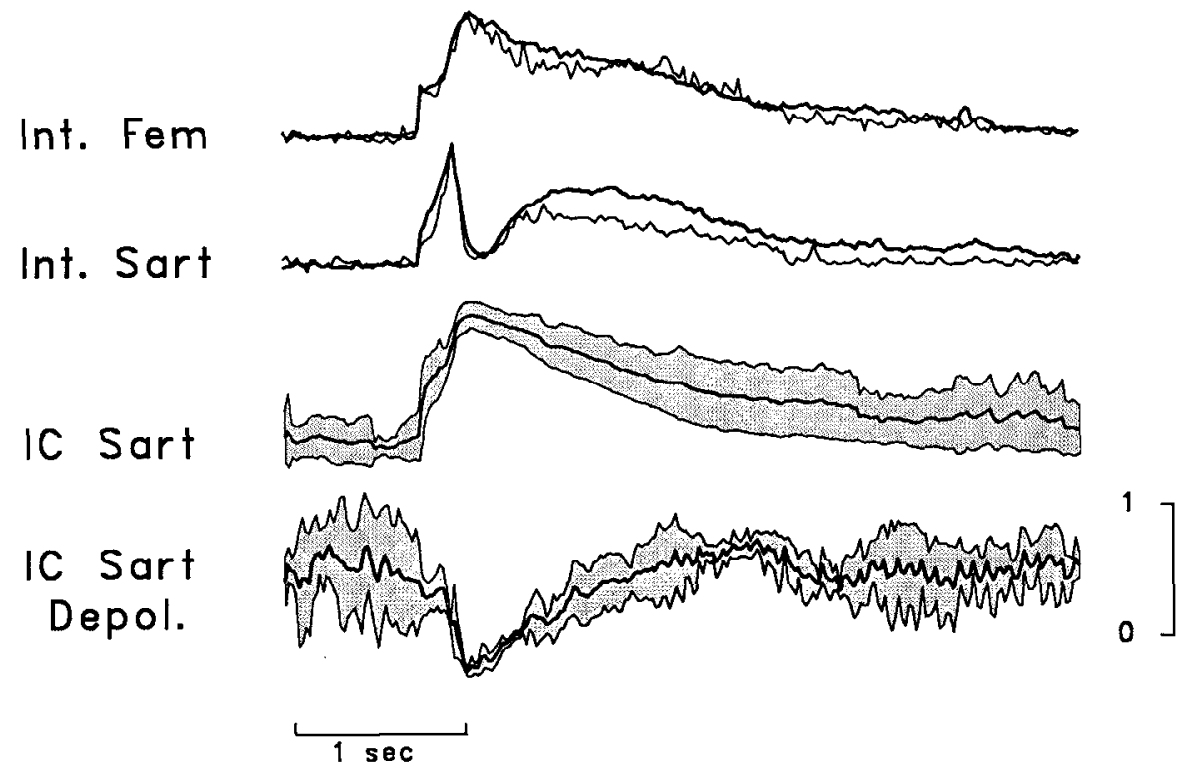

Figure 11. Single cycle intracellular averages (mean $\pm \mathrm{SD}$ ) from 3 sartorius motoneurons (IC Sart Depol.) during injection of depolarizing current $(0.5-$ $2.0 \mathrm{nA})$ sufficient to reverse the membrane potential during the pause in the sartorius nerve discharge. Also displayed are the control intracellular averages for sartorius motoneurons (same data as in Fig. 7), and the averaged integrated neurograms (labeled Int. Fem and Int. Sart). The neurograms displayed with the thick line were acquired with the control recordings, while those shown with the thinner line were obtained with the depolarized cells.

\section{Effects of current injection on the membrane potential in motoneurons}

Current was injected intracellularly into 8 motoneurons during episodes of motor activity to explore the voltage dependence of their depolarization. Unfortunately, difficulties in maintaining satisfactory electrode balance precluded measurement of reversal potentials. Nonetheless, in 5/7 flexorlike motoneurons (including $4 / 5$ identified sartorius motoneurons) depolarizing current injection reduced the amplitude of the depolarization and, if large enough, could reverse the direction of the membrane potential excursion during the pause in sartorius nerve discharge. The inhibitory nature of the reversed component was indicated by its ability to block the firing evoked by the depolarizing current. These findings are illustrated in Figure 10, which shows the effects of current injection on the first cycle of activity in a sartorius motoneuron. In this cell the reversed component of the synaptic potential coincided with the prominent depolarizing bump in the control recording and increased in amplitude with more negative current. Similar findings were obtained in $4 / 5$ sartorius motoneurons (and in one motoneuron that projected to the obturator nerve) and are summarized in the single cycle averages of Figure 11. This illustration combines the results from 3 different sartorius motoneurons in which depolarizing current $(0.5-2.0 \mathrm{nA})$ reversed the synaptic potential during the pause in sartorius discharge.

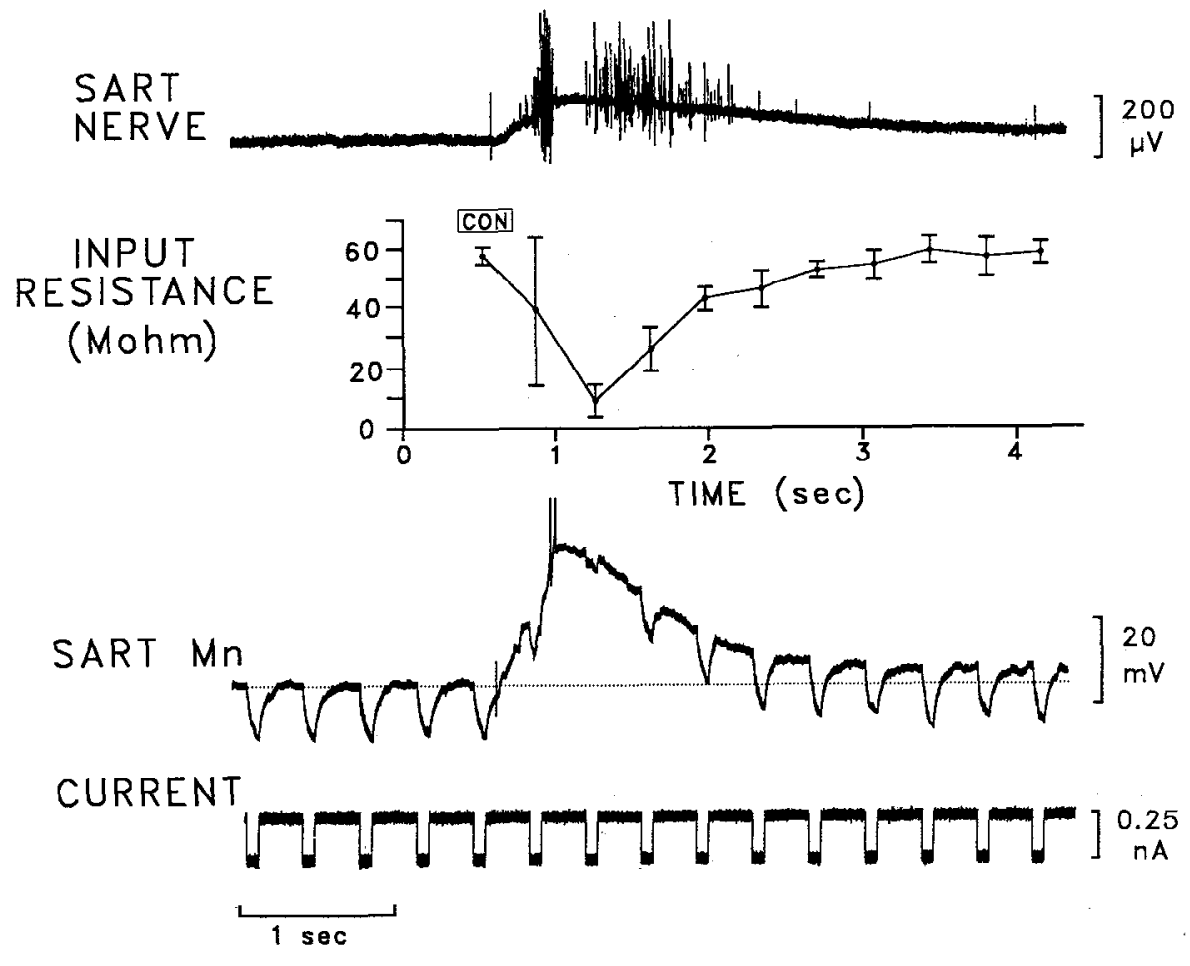

Figure 12. Measurement of input resistance in a sartorius motoneuron during a single cycle of motor activity. Top trace shows a wideband recording from the sartorius nerve (SART NERVE). Below this is a plot of the average resistance of the cell calculated from the voltage response to intracellular current pulses. Data from 5 cycles have been averaged together and are expressed as means \pm SD. The capacitative transients on the intracellular record (SART Mn) have been deleted for clarity. Same motoneuron as illustrated in Figure 10. Spikes are not displayed at full amplitude. 
Figure 13. Effects of intracellular current steps on the firing of motoneurons. $A$, Intracellular injection of depolarizing current into a sartorius motoneuron (same cell as illustrated in Figs. 10 and 12) produces steady firing with no evidence of a pause. Top trace in each set of records is a plot of the instantaneous firing frequency of the cell. $B$, Intracellular recording from a lateral motor column cell (presumed to be a motoneuron) that exhibited a pause in firing during motor activity. $C$, The cell shown in $B$ was depolarized by intracellular current to approximately the same membrane potential as during the burst but exhibited no pause in firing. Note also that the firing frequency of the cell was substantially higher during current injection than during synaptic activation.
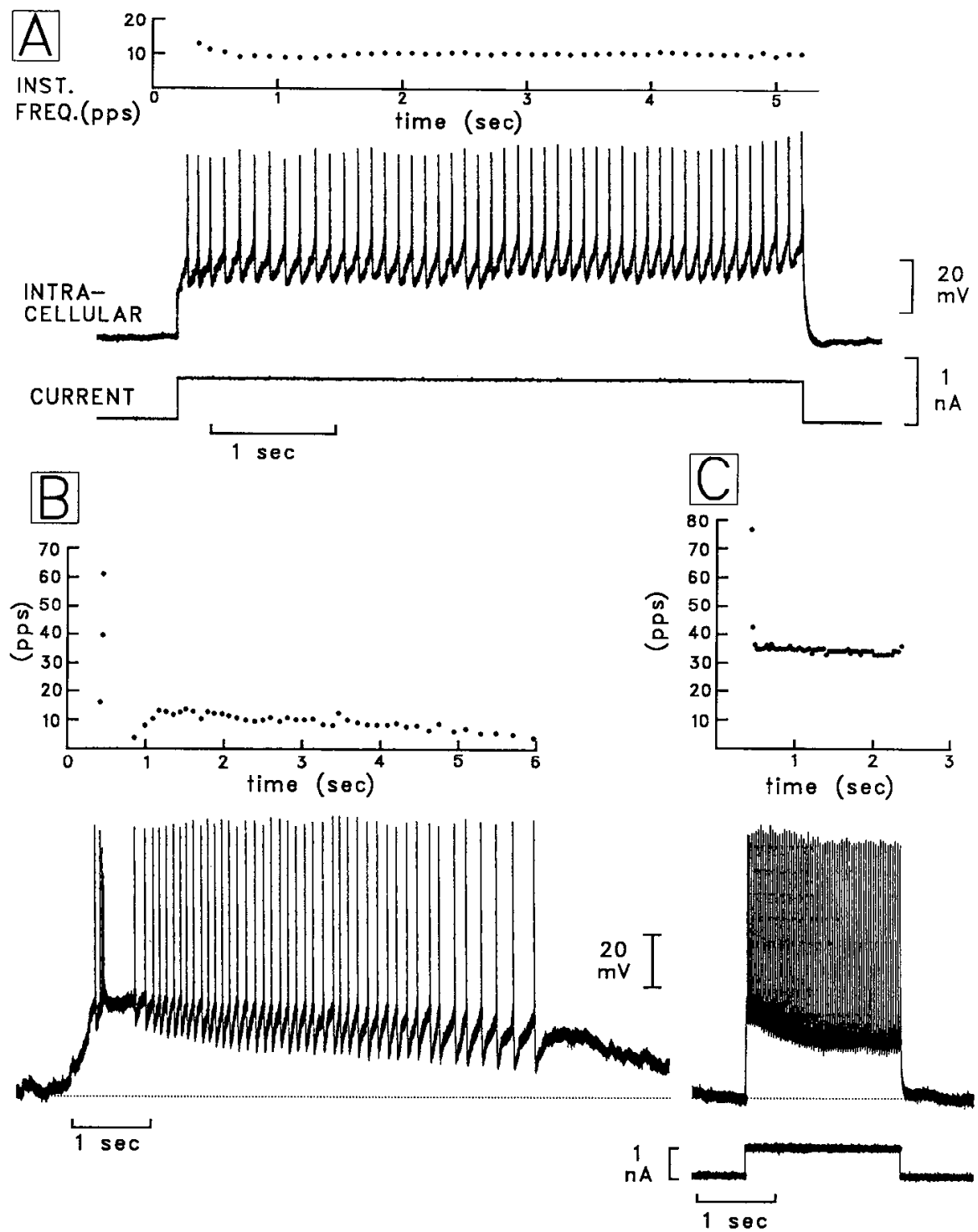

Taken together, these observations suggest that the depolarization in sartorius motoneurons is composed of both excitatory and inhibitory synaptic potentials and that the inhibitory potential is responsible for the pause in motoneuron firing. Apparently, the equilibrium potential for the IPSP is above rest, causing the potential to be depolarizing.

Current injection was also performed in another motoneuron identified from the ventral roots rather than the muscle nerve. The discharge behavior of this cell was characteristic of an extensor motoneuron because it exhibited no pause in firing. The amplitude of the depolarization was increased by injection of hyperpolarizing current and decreased by injection of depolarizing current. Moreover, peak depolarization exhibited an approximately linear relation with injected current, and there was no evidence of a reversal of part of the waveform (as in sartorius motoneurons) up to the maximum injected current of $0.2 \mathrm{nA}$. The maximum current injected into this cell was less than in other motoneurons and may have been insufficient to reverse an IPSP, although at this level of depolarization the motoneuron was firing repetitively at a similar rate to that in depolarized sartorius motoneurons that did exhibit reversal. It is important to note that extensor motoneurons, including the femorotibialis, can exhibit a brief pause in discharge. Thus, the finding of a brief hyperpolarization in one of the femorotibialis motoneurons suggests that this pause may also be mediated by synaptic inhibition as in flexor motoneurons.

\section{Mechanism of inhibition of motoneuron discharge}

During the depolarizing IPSP, the membrane putential was frequently above threshold for discharge, so that the inhibition of firing must be due to some other process associated with the IPSP. One possibility is that the membrane conductance increases significantly during the IPSP shunting action potential generation. This was suggested by the reduction in the amplitude and afterhyperpolarization of action potentials that occurred near the end of the pause (see Fig. 8). This hypothesis was investigated directly by making impedance measurements in 3 motoneurons (including 1 sartorius motoneuron) that exhibited a pause in firing. In these motoneurons the membrane impedance fell significantly from an average value of $61.7 \mathrm{M} \Omega$ in the resting membrane to minimum of $9 \mathrm{M} \Omega$ during the pause. This is illustrated for a sartorius motoneuron in Figure 12, which shows the results of injecting hyperpolarizing current pulses throughout the trajectory of the membrane potential during a 


\section{POSSIBLE CONNECTIONS}

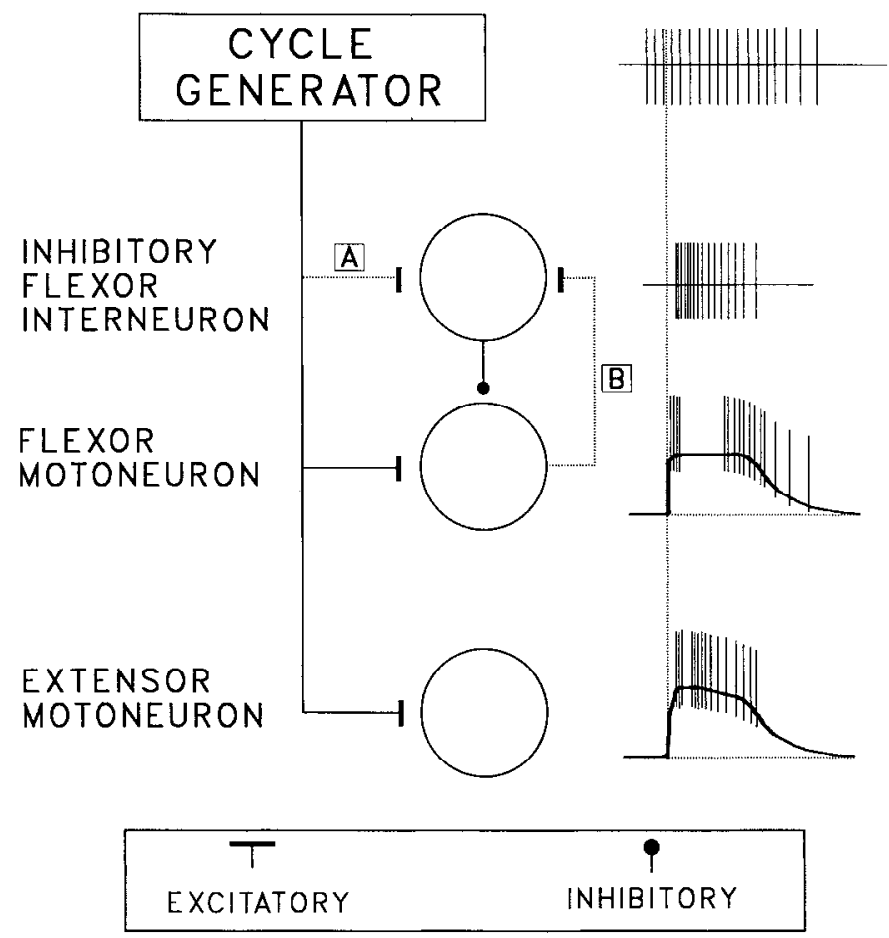

\section{PRESUMED FIRING PATTERNS}

Figure 14. Hypothetical model of neural connections that could explain the firing behavior of motoneurons in this study. The interneurons comprising the cycle generator are presumed to project monosynaptically to both flexor and extensor motoneurons. The inhibition of flexor motoneurons arises from a set of inhibitory interneurons that project monosynaptically to flexor motoneurons. The inhibitory interneuron could be driven either from the cycle generator ( $p a t h A$ ) or be part of the recurrent pathway to motoneurons (path $B$ ). The occurrence of a brief pause in some extensor motoneurons implies the existence of a weak extensor inhibitory system that is not illustrated. In the right column the firing pattern of the various cell classes during a single cycle of activity is illustrated, including those of the proposed flexor interneurons and the neurons of the CPG. single cycle of activity. The input impedance of this cell fell from a resting value of $57 \mathrm{M} \Omega$ to a minimum of $9 \mathrm{M} \Omega$ during the IPSP coincident with the pause in firing in the sartorius muscle nerve.

From these experiments it cannot be concluded that the large change in conductance is due solely to the IPSP. The concurrent EPSP and voltage-dependent membrane properties could also contribute to the total conductance change. Moreover, it is not clear whether the increased membrane conductance is both necessary and sufficient to account for the pause in firing. To test this idea it will be necessary to manipulate the conductance change in motoneurons and establish if this alters the duration or efficacy of inhibition. It is also possible that the pause in firing could be influenced by other factors in addition to the change in membrane conductance. For example, depolarization-induced inactivation of the spikc-gencrating mechanism might produce a transient pause in firing. This possibility was tested by injecting depolarizing current steps into 9 motoneurons and recording the pattern of their evoked discharge. In none of the cells tested was a pause in firing induced once sufficient current was injected to produce steady firing. In general, depolarizing current steps produced steady firing (see Fig. 13), and several cells that did not fire during synaptic depolarization did so during injected current. These findings suggest that the synaptic depolarization alone cannot account for the firing behavior of the neurons.

Another voltage-sensitive membrane property that might account for the pause in firing is a transient outward potassium current, commonly called A current. In many neuronal types, an A current activated by membrane depolarization can delay neuronal firing (Connor and Stevens, 1971; Getting, 1983; De- kin and Getting, 1984, 1987). Although the existence of this current has not been thoroughly investigated in the present experiments, in 3 cells a depolarizing step was preceded by a hyperpolarizing pulse to activate A current. None of these cells exhibited a significant pause compatible with the presence of $A$ current. While we cannot eliminate the possibility that A current is present in developing motoneurons, its participation in the genesis of the flexor firing pause is rendered unlikely anyway because the pause persists during depolarizing current injection (see Fig. 9A), which would inactivate A current.

\section{Discussion}

The excitatory drive responsible for motoneuron activity

Perhaps the most striking result to emerge from this study is that the alternating discharge of flexor and extensor motoneurons is not produced by a corresponding alternation in their depolarizing synaptic drive. Rather, the depolarization underlying motoneuron activity occurs at the same time in both sets of motoneurons. This surprising conclusion is supported by intracellular recording from individual flexor and extensor motoneurons and by recordings of population potentials in the corresponding muscle nerves. Although the depolarizing drive was similar in both categories of motoneuron in sartorius motoneurons, it appeared to be the sum of both a depolarizing excitatory and a depolarizing inhibitory potential.

The congruence of excitatory locomotor drive in antagonist motoneurons has not been described previously for adult motoneurons. Intracellular recording from motoneurons in adult vertebrates during fictive locomotion (Jordan, 1983; Perret, 1983; Russell and Wallen, 1983) or scratching (Berkinblit et al., 1980; Stein et al., 1982) has revealed that motoneuron discharge co- 
incides with phases of membrane depolarization that alternate with periods of hyperpolarization. Current and chloride injection into motoneurons has revealed the existence of postsynaptic inhibition during the hyperpolarization (Soffe and Roberts, 1982b; Perret, 1983; Russell and Wallen, 1983), although it is less clear if synaptic excitation also occurs during this phase.

Intracellular recordings from myotomal motoneurons in Xenopus embryos (Roberts and Kahn, 1982; Soffe and Roberts, 1982a) or DC-coupled ventral root recordings in bullfrog larvae (Stehouwer and Farel, 1985) have shown that contralateral (antagonist) motoneurons from the same segment are tonically depolarized at the same time during swimming episodes, although they fire out of phase. In both preparations, however, rhythmic oscillations of membrane potential are superimposed on the tonic depolarization that can account for the alternating discharge.

The similarity in the time course of the depolarization in flexor and extensor motoneurons raises the possibility that the antagonist motoneurons receive excitatory synaptic inputs from a common set of premotor interneurons. Although such connections are believed to be infrequent or weak in the adult spinal cord, they may be more common during development. Recent studies of the muscle afferent projection to motoneurons in embryonic chick (Koebbe and O'Donovan, 1985; Lee and O'Donovan, 1988) have shown that antagonist motoneurons are reciprocally excited by muscle afferent stimulation, although it is not yet clear whether such excitation is mediated monosynaptically. Similarly, Myklebust et al. (1986) have found evidence of reciprocal excitation of antagonist motoneurons by muscle spindle afferents in human neonates. These observations raise the possibility that common excitation of flexor and extensor motoneurons may be a general feature of embryonic development in higher vertebrates. Further studies will be necessary to reveal whether the common excitation of flexor and extensor motoneurons that characterizes in vitro motor activity is maintained after hatching.

\section{Role of synaptic inhibition in the phasing of flexor and extensor motor activity}

In most vertebrates studied to date, synaptic inhibition has been implicated in the phasing of flexor and extensor discharge during motor activity (for review, see Grillner and Wallen, 1985). The results of the present work suggest that synaptic inhibition also influences the phasing of activity in chick motoneurons, confirming pharmacological experiments implicating inhibition in the regulation of embryonic chick motility (Oppenheim and Reitzel, 1975; Sedlacek, 1976, 1982; Maderdrut et al., 1986).

One surprising aspect of synaptic inhibition in embryonic chick motoneurons is that it appears to be depolarizing. Although depolarizing IPSPs have been described previously in both embryonic chick (Velumian, 1984; see also Obata et al., 1978) and in neonatal rat motoneurons (Fulton et al., 1980; Takahashi, 1984; Jahr and Yoshioka, 1986), it was not clear from these studies whether the depolarizing IPSP was an artifact caused by chloride entry following cell penetration. In the chick cord this explanation can probably be excluded because the ventral root and muscle nerve recordings reveal entirely depolarizing potentials during motor activity. Moreover, picrotoxin- and strychnine-sensitive depolarizing potentials can be recorded intracellularly from motoneurons or extracellularly from the ventral roots following either muscle nerve (Lee et al., 1988) or ventral root stimulation (M. T. Lee and M. J. O'Donovan, unpublished observations).

Taken together these observations support the hypothesis that the reversal potential for IPSPs is above rest potential in these motoneurons. Thus, the very large conductance increase coincident with the IPSP may result in the membrane potential approaching the IPSP equilibrium potential during the pause in motoneuron discharge. Under these conditions, the ionic current underlying the IPSP may serve to clamp the membrane near the IPSP equilibrium potential and thereby prevent action potential generation.

It seems reasonable to postulate that the inhibitory synapses are electrotonically close to the soma. Such an idea is consistent with the ability to reverse the potential with somatic current injection and with the large decrease in membrane resistance measured at the soma. Recent studies of fictive locomotion in the adult cat have revealed that motoneuronal membrane resistance decreases during the hyperpolarizing phase of the locomotor drive potential, leading these authors to propose that the relevant inhibitory synapses are also electrotonically close to the soma (Schmidt et al., 1988).

A dendritically located inhibitory conductance might be complicated by large depolarizations propagating electrotonically into the soma, where they could excite impulse activity during the pause. Although it is worth noting that the large somatic depolarization, which $i$ electrotonically propagated into the axon (where it can be recorded), does not apparently cause axonal fring during the pause.

The evidence presented in this paper supports the idea that the pause in firing of sartorius motoneurons is mediated by synaptic inhibition. Since the majority of hindlimb flexor and extensor motoneurons also exhibit a pause in firing-it can be very short in extensors (Landmesser and O'Donovan, 1984)it seems reasonable to suppose that synaptic inhibition also mediates this pause, a suggestion supported by the finding of a brief hyperpolarization in 1 of the 5 extensor motoneurons that were recorded from. These observations suggest that the inhibitory interneurons responsible for the pause may also project weakly to extensor motoneurons. Such interneurons could be synaptically activated either by the central pattern generator or alternatively by motoneurons (see Fig. 14). The latter alternative raises the possibility that the inhibitory interneurons responsible for the pause might be similar to Renshaw cells in mammalian spinal cord. It is known that recurrent inhibition of motoneurons is functional in the chick cord by day 10 (Velumian, 1982), several days before the recordings in the present study were made. Moreover, depolarizing potentials can be recorded from ventral roots in the 13- to 15 -d-old chicks in response to stimulation of an adjacent ventral root that is blocked by cholinergic and inhibitory antagonists (M. T. Lee and M. J. O'Donovan, unpublished observations), suggesting that the recurrent pathway may have the same pharmacology in the chick as it does in mammals (Curtis and Ryall, 1966; Curtis et al., 1976). The large synchronous discharge that initiates each cycle of motor activity occurs in most hindlimb motoneurons (Landmesser and O'Donovan, 1984) and is therefore likely to be a potent activator of the recurrent pathway. In adult animals, recurrent inhibitory connections are generally not found between antagonist motor pools (for review, see Baldissera et al., 1981), although the distribution of recurrent inhibition between embryonic motor pools is unknown. Even if antagonist recurrent connections do not exist, recurrent inhibition could still influence the firing of a 
particular set of motoneurons and its close synergists, although this proposition would require that recurrent inhibition would be more effective in flexor than in extensor motoneurons. It is also possible more than one inhibitory pathway is responsible for the pause and the recurrent pathway simply augments other systems. Nevertheless, the recurrent system is promising for further studies because it can be selectively activated by antidromic stimulation of motoneurons and can be manipulated by the use of cholinergic and inhibitory antagonists.

One issue we have not addressed in this paper is whether the early termination of extensor activity is mediated by synaptic inhibition. Although no evidence was found for inhibition at the end of the extensor burst the issue was not pursued in depth, and it will require pharmacological and intracellular current injection experiments to resolve. Moreover, the question is complicated by the fact that in older embryos used for the intracellular studies the duration of femorotibialis activity tended to be more prolonged than at younger stages. Why this should be is not clear, but it was associated with a decrease in the duration of the pause in sartorius activity, raising the possibility that inhibitory pathways responsible for alternating discharge might become less effective in older embryos.

It is quite possible, however, that the early termination of extensor activity is mediated by other factors. For instance, one simple explanation is that the membrane potential in extensors falls below threshold earlier than that in flexors. This could occur if the extensor depolarization was systematically smaller than that in flexors, if spike threshold was higher than in flexor motoneurons or if the extensor depolarization decayed more rapidly than the flexor depolarization. In addition, voltage-sensitive membrane properties such as spike-frequency adaptation could also terminate extensor discharge early.

\section{Organization of excitatory and inhibitory projections to motoneurons}

In summary, the present results suggest that there are at least 2 sets of interneurons that participate in the generation of alternating motor activity in the chick cord. The first is the population of neurons responsible for the depolarizing excitatory drive to flexor and extensor motoneurons, and the second is a set of inhibitory interneurons producing the interruption of firing. The simplest hypothesis is that the excitatory interneurons project monosynaptically to both flexor and extensor motoneurons, whereas the inhibitory interneurons project predominantly to flexor motoneurons. Because some extensor motoneurons can also exhibit a brief pause in firing, it is necessary to propose that the postulated inhibitory interneurons also project weakly to extensor motoneurons. An obvious direction for further study is to search for these interneurons that may be identifiable on the basis of their firing patterns and synaptic projections to motoneurons (see Fig. 14).

\section{References}

Baldissera, F., H. Hultborn, and M. Illert (1981) Integration in spinal neuronal systems. In Handbook of Physiology, Sec. 1, The Nervous System, Vol. 2, Motor Control, Part 1, V. B. Brooks, ed., pp. 509594, American Physiological Society, Bethesda, MD.

Barry, M., and M. J. O'Donovan (1987) The effects of excitatory amino acids and their antagonists on the generation of motor activity in the isolated chick cord. Dev. Brain Res. 36: 271-276.

Bekoff, A. (1976) Ontogeny of leg motor output in the chick embryo: A neural analysis. Brain Res. 106: 271-291.
Bekoff, A., P. S. G. Stein, and V. Hamburger (1975) Coordinated motor output in the hindlimb of the 7-day-old chick embryo. Proc. Natl. Acad. Sci. USA 72: 1245-1248.

Berkinblit, M. B., T. G. Deliagina, G. N. Orlovsky, and A. G. Feldman (1980) Activity of motoneurons during fictitious scratch reflex. Brain Res. 193: 427-438.

Brimk, E., P. J. Harrison, E. Jankowska, D. A. Mccrea, and B. Skoog (1983) Post-synaptic potentials in a population of motoneurons following activity of single interneurons in the cat. J. Physiol. (Lond.) 343: 341-359.

Connor, J. A., and C. F. Stevens (1971) Prediction of repetitive firing behavior from voltage clamp data on an isolated neuron soma. $J$. Physiol. (Lond.) 213: 31-53.

Curtis, D. R., and R. W. Ryall (1966) The acetylcholine receptors of Renshaw cells. Exp. Brain Res. 2: 66-80.

Curtis, D. R., C. J. A. Game, D. Lodge, and R. M. McCulloch (1976) A pharmacological study of Renshaw inhibition. J. Physiol. (Lond.) 258: 227-242.

Dekin, M. S., and P. A. Getting (1984) Firing pattern of neurons in the nucleus tractus solitarius: Modulation by membrane hyperpolarization. Brain Res. 324: 180-184.

Dekin, M. S., and P. A. Getting (1987) In vitro characterization of neurons in the ventral part of the nucleus tractus solitarius. Identification of neuronal types and repetitive firing properties. J. Neurophysiol. 58: 195-214.

Fulton, B. P., R. Miledi, and T. Takahashi (1980) Electrical synapses between motoneurons in the spinal cord of the newborn rat. Proc. $R$. Soc. London [Biol.] 208: 115-120.

Getting, P. A. (1983) Mechanisms of pattern generation underlying swimming in Tritonia. III. Intrinsic and synaptic mechanisms for delayed excitation. J. Neurophysiol. 49: 1036-1050.

Grillner, S., and P. Wallen (1985) Central pattern generators for locomotion, with special reference to vertebrates. Annu. Rev. Neurosci. 8: 233-261.

Jacobson, R. D., and M. Hollyday (1982a) A behavioral and electromyographic study of walking in the chick. J. Neurophysiol. 48: 238256.

Jacobson, R. D., and M. Hollyday (1982b) Electrically evoked walking and fictive locomotion in the chick. J. Neurophysiol. 48: 257-270.

Jahr, C. E., and K. Yoshioka (1986) 1a afferent excitation of motoneurons in the in vitro new-born rat spinal cord is selectively antagonized by kynurenate. J. Physiol. (Lond.) 370: 515-530.

Jordan, L. M. (1983) Factors determining motoneuron rythmicity during fictive locomotion. Symp. Soc. Exp. Biol. 37: 423-444.

Koebbe, M. J., and M. J. O'Donovan (1985) Properties and distribution of muscle afferent projections to lumbosacral motoneurons in the spinal cord of the chick embryo. Soc. Neurosci. Abstr. 13: 78.

Landmesser, L. T. (1978) The distribution of hindlimb motoneurons supplying chick hindlimb muscles. J. Physiol. (Lond.) 284: 371-389.

Landmesser, L. T., and M. J. O'Donovan (1984) Activation patterns of embryonic chick hindlimb muscles recorded in-ovo and in an isolated spinal cord preparation. J. Physiol. (Lond.) 347: 189-204.

Lee, M. T., and M. J. O'Donovan (1988) Excitatory sensorimotor connections between antagonists in the isolated chick embryo spinal cord. Soc. Neurosci. Abstr. 14: 579.

Lee, M. T., M. J. Koebbe, and M. J. O'Donovan (1988) The development of sensorimotor synaptic connections in the lumbosacral cord of the chick embryo. J. Neurosci. 8: 2530-2543.

Luscher, H.-R., P. Ruenzel, E. Fetz, and E. Henneman (1979) Postsynaptic population potentials recorded from ventral roots perfused with isotonic sucrose: Connections of groups Ia and II spindle afferent fibers with large populations of motoneurons. J. Neurophysiol. 42: 1146-1164.

Maderdrut, J. L., J. L. Reitzel, and R. W. Oppenheim (1986) Further behavioral analysis of GABA-mediated inhibition in the early chick embryo. Dev. Brain Res. 25: 157-160.

McLennan, I. S. (1983) Neural dependence and independence of myotube production in chicken hind limb muscles. Dev. Biol. 98: 287294.

Myklebust, B. M., G. L. Gottlieb, and G. C. Agarwal (1986) Stretch reflexes of the normal human infant. Dev. Med. Child Neurol. 28 $440-449$.

Obata, K., M. Oide, and H. Tanaka (1978) Excitatory and inhibitory actions of GABA and glycine on embryonic chick spinal neurons in culture. Brain Res. 144: 179-184.

O'Donovan, M. J. (1986) Intracellular recordings from embryonic 
motoncurons during cvoked and spontancous motor activity. Soc. Neurosci. Abstr. 12: 1117.

O'Donovan, M. J. (1987a) Developmental approaches to the analysis of vertebrate central pattern generators. J. Neurosci. Methods 21: 275-286.

O'Donovan, M. J. (1987b) In vitro methods for the analysis of motor function in the developing spinal cord of the chick embryo. Med. Sports. Sci. Exer. 19: S130-S133.

O'Donovan, M. J., and L. T. Landmesser (1987) The development of hindlimb motor activity studied in an isolated preparation of the chick spinal cord. J. Neurosci. 7: 3256-3264.

Oppenheim, R. W., and J. L. Reitzel (1975) Ontogeny of behavioral sensitivity to strychnine in the chick embryo: Evidence for the early onset of CNS inhibition. Brain Behav. Evol. 11: 130-159.

Pcrrct, C. (1983) Centrally gencrated pattern of motoncuron activity during locomotion in the cat. Symp. Soc. Exp. Biol. 37: 405-422.

Pittman, R., and R. W. Oppenheim (1979) Cell death of motoneurons in the chick embryo spinal cord. IV. Evidence that a functional neuromuscular interaction is involved in the regulation of naturally occurring cell death and the stabilization by synapses. J. Comp. Neurol. 187: 425-446.

Provine, R. R. (1972) Ontogeny of bioelectric activity in the spinal cord of the chick embryo and its behavioral implications. Brain Res. 41: 365-378.

Provine, R. R. (1973) Neurophysiological aspects of behavior development in the chick embryo. In Behavioral Embryology, Vol. 1, G. Gottlieb, ed., pp. 77-102, Academic, New York.

Renaud, D., G. H. Le Douarin, and A. Khaskiye (1978) Spinal cord stimulation in chick embryo: Effects on development of the posterior latissimus dorsi muscle and neuromuscular junctions. Exp. Neurol. 60: 189-200.

Ripley, K. L., and R. R. Provine (1972) Neural correlates of embryonic motility in the chick. Brain Res. 45: 127-134.

Roberts, A., and J. A. Kahn (1982) Intracellular recordings from spinal neurons during swimming in paralysed frog embryos. Phil. Trans. R. Soc. London [Biol.] 299: 213-228.

Russell, D. F., and P. Wallen (1983) On the control of myotomal motoncurons during "fictive swimming" in the lamprey spinal cord in vitro. Acta Physiol. Scand. 117: 161-170.

Schmidt, B. J., D. E. R. Meyers, J. W. Fleshman, M. Tokuriki, and R. E. Burke (1988) Phasic modulation of short latency cutaneous excitation in flexor digitorum longus motoneurons during fictive locomotion. Exp. Brain Res. 71: 568-578.

Sedlacek, J. (1976) Development of spontaneous motility in chick embryos. Normal development and the activating effect of strychnine and picrotoxin. Physiol. Bohemoslov. 25: 505-509.

Sedlacek, J. (1982) Glycine- and GABA-ergic elements in the development of embryonic spontaneous motility. Physiol. Bohemoslov. 31: 329-339.

Soffe, S. R., and A. Roberts (1982a) Activity of myotomal motoneurons during fictive swimming in frog embryos. J. Neurophysiol. 48: 1274-1278.

Soffe, S. R., and A. Roberts (1982b) Tonic and phasic synaptic input to spinal cord motoneurons during fictive locomotion in frog embryos. J. Neurophysiol. 48: 1279-1288.

Stehouwer, D. J., and P. B. Farel (1985) Development of locomotor mechanisms in the frog. J. Neurophysiol. 53: 1453-1465.

Stein, P. S. G., G. A. Robertson, J. Keifer, M. L. Grossman, J. A. Berenbeim, and P. R. Lennard (1982) Motoneuron synaptic potentials during fictive scratch reflex in turtle. J. Comp. Physiol. 146: 401409.

Takahashi, T. (1984) Inhibitory miniature synaptic potentials in rat motoneurons. Proc. R. Soc. London [Biol.] 221: 103-109.

Toutant, J. P., M. N. Toutant, D. Renaud, and G. H. Le Douarin (1979) Enzymatic differentiation of muscle fiber types in embryonic latissimus dorsi of the chick: Effects of spinal cord stimulation. Cell. Diff. $8: 375-382$.

Velumian, A. A. (1981) Intracellular recordings from chick motoneurons in the isolated perfused spinal cord. Brain Res. 229: 502-506.

Velumian, A. A. (1982) Recurrent inhibition in avian spinal motoneurones. Dokl. Akad. Nauk. SSSR 263: 1500-1502 [in Russian, cited in Velumian (1984)].

Velumian, A. A. (1984) Direct evidence for postsynaptic inhibition in the embryonic chick spinal cord. Dev. Brain Res. 14: 229-239. 